\title{
Article
}

\section{Proliposome Tablets Manufactured Using A Slurry-Driven Lipid-Enriched Powders: Development, Characterization and Stability Evaluation}

Khan, Iftikhar, Yousaf, Sakib, Subramanian, Sneha, Albed Alhnan, Mohamed, Ahmed, Waqar and Elhissi, Abdelbary

Available at http://clok.uclan.ac.uk/21495/

Khan, Iftikhar, Yousaf, Sakib, Subramanian, Sneha, Albed Alhnan, Mohamed, Ahmed, Waqar and Elhissi, Abdelbary (2018) Proliposome Tablets

Manufactured Using A Slurry-Driven Lipid-Enriched Powders: Development, Characterization and Stability Evaluation. International Journal of Pharmaceutics. ISSN 0378-5173

It is advisable to refer to the publisher's version if you intend to cite from the work. http://dx.doi.org/10.1016/j.ijpharm.2017.12.049

For more information about UCLan's research in this area go to http://www.uclan.ac.uk/researchgroups/ and search for <name of research Group>.

For information about Research generally at UCLan please go to http://www.uclan.ac.uk/research/

All outputs in CLoK are protected by Intellectual Property Rights law, including Copyright law. Copyright, IPR and Moral Rights for the works on this site are retained by the individual authors and/or other copyright owners. Terms and conditions for use of this material are defined in the policies page. 


\section{Accepted Manuscript}

Proliposome Tablets Manufactured Using A Slurry-Driven Lipid-Enriched Powders: Development, Characterization and Stability Evaluation

Iftikhar Khan, Sakib Yousaf, Sneha Subramanian, Mohamed Albed Alhnan, Waqar Ahmed, Abdelbary Elhissi

PII: $\quad$ S0378-5173(17)31193-6

DOI: $\quad$ https://doi.org/10.1016/j.ijpharm.2017.12.049

Reference: $\quad$ IJP 17241

To appear in: $\quad$ Indian Journal of Pharmacology

Received Date: $\quad 12$ October 2017

Revised Date: $\quad 20$ December 2017

Accepted Date: $\quad 30$ December 2017

Please cite this article as: I. Khan, S. Yousaf, S. Subramanian, M. Albed Alhnan, W. Ahmed, A. Elhissi, Proliposome Tablets Manufactured Using A Slurry-Driven Lipid-Enriched Powders: Development, Characterization and Stability Evaluation, Indian Journal of Pharmacology (2017), doi: https://doi.org/10.1016/j.ijpharm.2017.12.049

This is a PDF file of an unedited manuscript that has been accepted for publication. As a service to our customers we are providing this early version of the manuscript. The manuscript will undergo copyediting, typesetting, and review of the resulting proof before it is published in its final form. Please note that during the production process errors may be discovered which could affect the content, and all legal disclaimers that apply to the journal pertain. 


\section{Proliposome Tablets Manufactured Using A Slurry-Driven Lipid-Enriched Powders: Development, Characterization and Stability Evaluation}

${ }^{*}$ Iftikhar Khan ${ }^{\text {a, b, c }}$, Sakib Yousaf ${ }^{\text {b, c }}$, Sneha Subramanian ${ }^{\text {b, c }}$, Mohamed Albed Alhnan ${ }^{\text {b, c }}$, Waqar Ahmed $^{\mathrm{d}}$, ${ }^{*}$ Abdelbary Elhissi ${ }^{\mathrm{e}}$

${ }^{a}$ School of Pharmacy and Biomolecular Sciences, Liverpool John Moores University, Liverpool, L3 3AF, United Kingdom

${ }^{\mathrm{b}}$ Institute of Nanotechnology and Bioengineering, University of Central Lancashire, Preston PR1 2HE, United Kingdom

'School of Pharmacy and Biomedical Sciences, University of Central Lancashire, Preston PR1 2HE, United Kingdom

${ }^{d}$ School of Mathematics and Physics, College of Science, University of Lincoln, Lincoln, LN6 7TS, UK. ePharmaceutical Sciences Section, College of Pharmacy, Qatar University, P.O. Box 2713, Doha, Qatar

${ }^{*}$ Corresponding authors:

Dr. Abdelbary Elhissi

Research Excellence Department

Office of the Vice President for Reserarch and Graduate Studies

Qatar University, P.O. Box 2713, Doha, Qatar and

Pharmaceutical Sciences Section, College of Pharmacy

Qatar University, P.O. Box 2713, Doha, Qatar

T: +97444035632

E: aelhissi@qu.edu.qa, aelhissi@gmail.com

Dr. Iftikhar Khan

School of Pharmacy and Biomolecular Sciences

Liverpool John Moores University

Byrom Street

L3 3AF

UK

T: (+44) 1512312736

E: I.Khan@ljmu.ac.uk, iftikharkhans@yahoo.com 


\section{Abstract}

Proliposome powders were prepared via a slurry method using sorbitol or D-mannitol as carbohydrate carriers in $1: 10$ or $1: 15 \mathrm{w} / \mathrm{w}$ lipid phase to carrier ratios. Soya phosphatidylcholine (SPC) and cholesterol were employed as a lipid phase and Beclometasone dipropionate (BDP) was incorporated as a model drug. Direct compaction using a Minipress was applied on the lipid-enriched powder in order to manufacture proliposome tablets. Sorbitol-based proliposome tablets in a 1:15 w/w ratio were found to be the best formulation as it exhibited excellent powder flowability with an angle of repose of $25.62 \pm 1.08^{\circ}$, and when compacted the resultant tablets had low friability $(0.20 \pm 0.03 \%)$, appropriate hardness (crushing strength) $(120.67 \pm 12.04 \mathrm{~N})$, short disintegration time $(5.85 \pm 0.66 \mathrm{~min})$, and appropriate weight uniformity. Moreover, upon hydration into liposomes, the entrapment efficiency for sorbitol formulations in both $1: 10$ and 1:15 lipid to carrier ratios were significantly higher (53.82 \pm $6.42 \%$ and $57.43 \pm 9.12 \%)$ than D-mannitol formulations $(39.90 \pm 4.30 \%$ and $35.22 \pm 6.50 \%)$, respectively. Extended stability testing was conducted for 18 months, at three different temperature conditions (Fridge Temperature $\left(\mathrm{FT} ; 6^{\circ} \mathrm{C}\right)$, Room Temperature $\left(\mathrm{RT} ; 22^{\circ} \mathrm{C}\right)$ and High Temperature $\left.\left(\mathrm{HT} ; 40^{\circ} \mathrm{C}\right)\right)$ for sorbitol-based proliposome tablets $(1: 15 \mathrm{w} / \mathrm{w}$ ratio). Volume median diameter (VMD) and zeta potential significantly changed from $5.90 \pm 0.70 \mu \mathrm{m}$ to $14.79 \pm 0.79 \mu \mathrm{m}$ and from $-3.08 \pm$ $0.26 \mathrm{mV}$ to $-11.97 \pm 0.26 \mathrm{mV}$ respectively at month 18 , when samples were stored under HT conditions. Moreover, the entrapment efficiency of BDP decreased from $57.43 \pm 9.12 \%$ to $17.93 \pm$ $5.37 \%$ following 18 months storage under HT conditions. Overall, in this study for the first time, proliposome tablets were manufactured and thoroughly characterized, and sorbitol showed to be a promising carrier.

\section{Key words}

Liposome; Proliposome; Beclometasone dipropionate; Sorbitol; D-mannitol; Tablets 


\section{INTRODUCTION}

Liposomes are commonly used as carriers for many pharmaceutically active compounds; these, if hydrophobic, are entrapped into the liposome bilayers, or, if hydrophilic, into the central aqueous core of the liposome. Although liposomes are established drug carriers, they exhibit instability during storage (Hunt and Tsang, 1981, Khan et al., 2013, Khan et al., 2016), resulting in drug leakage, as well as aggregation and fusion of the liposome vesicles (Wong and Thompson, 1982). In order to overcome these issues, liposomes have been generated from stable dry formulations known as proliposomes (Payne et al., 1986b, Payne et al., 1986a, Khan et al., 2015). Proliposomes are comprised of a lipid component (e.g. phospholipid, cholesterol and drug), which forms a thin film coated onto carbohydrates carrier particles (Payne et al., 1986b). These proliposomes are then hydrated to form liposomes via addition of an aqueous solvent.

Many formulations are available in powder form due to their mechanical feasibility and stability. However, powder formulations are typically challenging to manage in terms of large scale manufacture, owing to their bulkiness; in addition to health and environmental risks associated with ultrafine solids that might be present in the powder (EPA, 2013). For the aforementioned reasons, powders are commonly tableted, offering a plethora of benefits, including simplicity and economic feasibility of preparation, stability and convenience in handling, packaging and dispensing (Saker and Alanazi, 2013).

The strength exhibited by tablets is heavily dependent upon preparation technique and importantly, the composition of the powder (Sinka et al., 2009). In addition to the active pharmaceutical ingredient (API), diluent excipients used in powder and tablet manufacture are typically safe additives such as carbohydrates. Furthermore, small concentrations of functional additives such as disintegrants and glidants are incorporated (Rojas et al., 2014). Tablets are considered economical to manufacture (Sastry et al., 2000, Jivraj et al., 2000), being one of the most widely available formulations in the pharmaceutical industry. A key advantage associated with preparing medicines in the form of tablets is the preserved stability of the drug. Many tablets are inherently stable due to the omission of certain ingredients, or presence of certain thermo or moisture stable excipients.

This work aims to develop and assess proliposome powders that can be compressed into tablets using a slurry-based approach we published recently to manufacture the proliposomes (Khan et al., 2015, Khan et al., 2017). Two individual proliposome formulations, with varying carbohydrate carrier (sorbitol or D-Mannitol) and lipid to carrier ratio (i.e. 1:10 and 1:15 w/w) were investigated, and the influence of proliposome powder flowability on compressibility into tablets was explored. Furthermore, the resultant tablets were characterized and checked against standard quality control (QC) tests including weight uniformity, disintegration time, Hardness testing (i.e. crushing strength) and friability testing in concordance to BP and USP standards. Moreover, entrapment studies were conducted to evaluate the potential of the proliposome tablets at providing controlled release of the model 
antiasthma drug Beclomethasone dipropionate (BDP). Formulations were stored for 18 months using three different temperatures, and subsequently $Q C$ tests were performed; and following hydration with aqueous phase to generate liposomes, size and zeta potential were analysed to evaluate formulation stability. This is the first study that employed the slurry-based proliposome method to generate tablets with extended stability studies of 18 months.

\section{MATERIALS AND METHODS}

\subsection{Materials}

Sorbitol $(250-700 \mu \mathrm{m}$; water solubility $=2350 \mathrm{mg} / \mathrm{ml})$, ferric chloride and ammonium thiocyanate were purchased from VWR (BDH Prolab), UK. D-mannitol ( $\geq 98 \% ;<250 \mu \mathrm{m}$; water solubility $=100$ $\mathrm{mg} / \mathrm{ml}$ ), Beclometasone dipropionate (BDP, $\geq 99 \%)$, cholesterol $(\geq 99 \%)$ and Deuterium oxide $\left(\mathrm{D}_{2} \mathrm{O}\right.$, $1.105 \mathrm{~g} / \mathrm{ml}$ density and $99.8 \%$ purity) were purchased from Sigma-Aldrich, UK. Soya phosphatidylcholine (SPC; Lipoid S-100; 94\% purity) was a gift from Lipoid, Steinhausen, Switzerland. HPLC-grades of methanol and water were supplied by Fischer Scientific Ltd, UK, and absolute ethanol and chloroform (AnalaR grade) were purchased from Fischer Scientific Ltd., UK.

\subsection{Manufacture of proliposomes powder using the "Slurry" method}

Proliposomes were manufactured in using the "Slurry" method (Khan et al., 2015, Khan et al., 2017). Sorbitol or D-mannitol were chosen as carbohydrate carriers. SPC and cholesterol were incorporated in a 1:1 mole ratio as a lipid phase $(250 \mathrm{mg})$, and BDP was included at $2 \mathrm{~mole} \%$ of the lipid phase. Two different formulation ratios were prepared for each carrier; 1:10 and 1:15 w/w lipid to carrier. In the preparation of $1: 10 \mathrm{w} / \mathrm{w}$ lipid to carrier ratio proliposome formulation, $2.50 \mathrm{~g}$ of carbohydrate carrier was added in a pear-shaped flask $(100 \mathrm{ml})$. Lipid phase was prepared by dissolving the lipid constituents in ethanol, so that the overall concentration of solid constituents dispersed or dissolved in ethanol was $333 \mathrm{mg} / \mathrm{ml}$. The resultant alcoholic solution with or without BDP was then poured onto the carbohydrate carrier in the round-bottom flask. Similarly, for the $1: 15 \mathrm{w} / \mathrm{w}$ formulation ratios, 3.75 $\mathrm{g}$ of carbohydrate was used, and the remaining excipients were kept constant. The pear-shaped flask was then attached to a rotary evaporator (Buchi Rotavapor R-114, Buchi, Switzerland), partially immersed in a water bath that was previously adjusted to $45^{\circ} \mathrm{C}$ (Buchi Waterbathe B-480, Buchi, Switzerland). A vacuum pump (Buchi Vac V-501) was used to evaporate the ethanol with a maximum rotation speed of $280 \mathrm{rpm}$ for $2 \mathrm{~h}$. Subsequently, the generated negative pressure was released and the flask was detached from the rotary evaporator. The yielded dry powder (i.e. proliposomes) was collected and stored in an air-tight container at $-18^{\circ} \mathrm{C}$ for subsequent studies.

\subsection{Lipid quantification via the Stewart assay}


Lipid quantification was performed using the Stewart assay (Stewart, 1980). Liposome samples (1 ml) were individually hydrated from sorbitol or D-mannitol-based proliposomes, each sample was placed in a centrifuge tube and ethanol was added to convert the liposome suspension into an ethanolic lipid solution. The samples were placed at $90^{\circ} \mathrm{C}$ in an oven overnight to evaporate the ethanol and obtain a lipid deposit. Chloroform $(2 \mathrm{ml})$ and ammonium ferrothiocyanate solution $(2 \mathrm{ml}$ ) (prepared by dissolving $7.60 \mathrm{~g}$ of ammonium thiocyanate and $6.76 \mathrm{~g}$ of ferric chloride in deionised water up to 250 $\mathrm{ml}$ ) was poured into the centrifuge tube. Vortex-mixing (Fision WhirliMixer, Fision scientific equipment, Leicestershire, UK) was conducted for $1 \mathrm{~min}$, followed by $5 \mathrm{~min}$ of centrifugation with a speed of $300 \mathrm{~g}$ at $4^{\circ} \mathrm{C}$ via a bench centrifuge (Jouan B4i, Thermo Electron Corporation, UK). The chloroform layer containing the lipid was separated and quantified via UV-Visible Spectrophotometer at $488 \mathrm{~nm}$ (Jenway, 7315, Bibby Scientific Ltd, UK) against a calibration curve constructed using lipid dissolved in chloroform $(40-80 \mu \mathrm{g} / \mathrm{ml})$.

\subsection{Compressibility index and Hausner ratio determination via tapped density studies}

A graduated cylinder with $1 \mathrm{ml}$ increments and a volume of $50 \mathrm{ml}$ was implemented to test the powdered sample (USP., 2015b, BP., 2016d). A set amount of $15 \mathrm{~g}$ (either coarse carrier or proliposome powder) was transferred into the cylinder, after which the graduated cylinder was tapped manually on a hard surface for 2 - 3 repetitions in order to level the formulation. Then, the initial or unsettled apparent volume $\left(\mathrm{V}_{0}\right)$ of the powder was noted. The cylinder was then affixed to a tapped density tester (Agilent technologies, USA) for automated controlled tapping. The apparatus was set at a rate of $1500 \pm 15$ taps for 5 min (i.e. $300 \pm 15$ taps per $\mathrm{min}$ ) and the height from which the cylinder was tapped (14 $\pm 2 \mathrm{~mm}$ ) was fixed. Post tapping, the final tapped volume $\left(\mathrm{V}_{\mathrm{f}}\right)$ was recorded. Both compressibility index (Equation 1) and Hausner ratio (Equation 2) were calculated from values generated from the tapped density experiments (i.e. $V_{0}$ and $V_{f}$ ).

Carr's scale exhibits (Table 1) the degree or quality of powder flow in correspondence to values given in compressibility index and hausner ratio, which indicate powder characteristics (Carr, 1965).

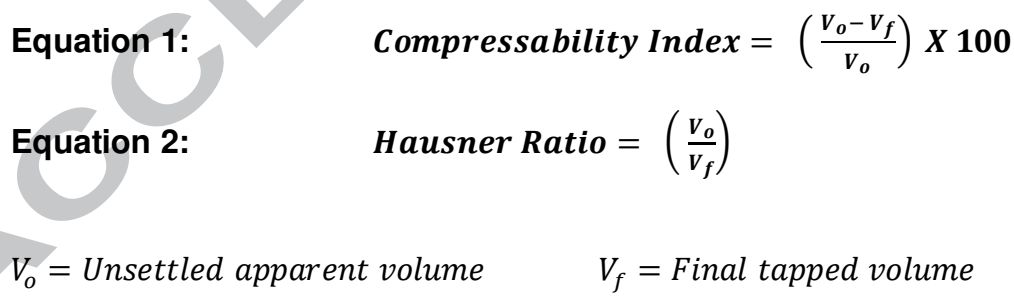

\subsection{Angle of repose (AOR)}

Coarse carbohydrate or proliposome powder $(15 \mathrm{~g})$ were put forward for testing. Powder was allowed to pass through a funnel at a set height $(2-4 \mathrm{~cm})$, allowing for the formation of a cone. During cone formation, the funnel was elevated between the set height range $(2-4 \mathrm{~cm})$ in order to maintain a 
constant distance from the powder cone as it formed (BP., 2016c). Any improper or asymmetrical cone formation was discarded and the measurement repeated until uniform cone formation was achieved. A level and smooth surface was ensured for this process. Upon successful cone formation, the angle formed through the formation process was established using a protractor, which was kept parallel to the base of the cone to measure the AOR (Wong, 2002). Generated values were used to classify the powders in accordance to Carr's scale.

\subsection{Direct compression of proliposome powder}

Proliposome powders were employed to manufacture novel proliposome tablets using a Riva Minipress MII SA single punch machine (Cenova 4018 Ciudadela, Buenos Aires, Argentina). Tablets were prepared using the provided punches $(6 \mathrm{~mm}$ in diameter). Tablets were typically weighed between an average of $90.17 \pm 4.30-91.97 \pm 2.81 \mathrm{mg}$ for sorbitol-based proliposome and $91.44 \pm$ $4.21-92.16 \pm 3.60 \mathrm{mg}$ for D-mannitol-based proliposome tablets (1:10 and 1:15 w/w lipid to carrier ratios, with and without BDP). Proliposome tablets (from sorbitol-based proliposome powder with 1:15 $\mathrm{w} / \mathrm{w}$ lipid to carrier ratio) manufactured through single punch machine via automated route were manufactured at a rate of $20 \pm 4$ tablets per min, and with a compressive force ranging between 3.00 and $4.50 \mathrm{kN}$. Manufacturing conditions were the same for all formulations tested.

\subsection{Uniformity of weight (Weight variation)}

Ten tablets were selected randomly from each batch; each tablet was weighed individually using a calibrated balance (PI-225DA Denver Instruments, Germany). The mean weight of these tablets was then ascertained using equation 3 , and the variance of each tablet from the mean weight was calculated (BP., 2016e).

Equation 3: $\quad$ Average weight $=\left(\frac{X_{1}+X_{2}+X_{3}+X_{1}+\cdots X_{20}}{10}\right)$

' $\mathrm{X}$ ' is weight of individual tablet

\subsection{Disintegration testing}

An Erweka disintegration tester (GmbH, type TBH 220D, D-63150 Heusenstamm, Germany) was used to study the disintegration time of tablets. The rack assembly was placed in $1,000 \mathrm{ml}$ glass beaker filled with deionized water up to the level $(800-900 \mathrm{ml})$, where it was covering a distance of $55 \pm 2 \mathrm{~mm}$ in the beaker. Thermostatic arrangement was ensured by maintaining the temperature at $37^{\circ} \mathrm{C}$. Six proliposome tablets were placed in six tubes individually, followed by positioning of the six small plastic disks over the tablets (USP., 2015a, BP., 2016a). Disintegration time was noted for tablets tested, in triplicate. 


\subsection{Tablets hardness (crushing strength)}

A specialised Erweka hardness tester (GmbH, type TBH 220D, D-63150 Heusenstamm, Germany) was employed to measure the mechanical integrity (breaking force) of the proliposome tablets. Prior to assessment of tablet hardness, the machine was calibrated with no tablets, followed by assessment of the crushing strength (measured in Newton) of ten randomly selected proliposome tablets.

\subsection{Friability testing}

Proliposome tablets $(6.5 \mathrm{~g})$ were selected randomly; cleaned, weighed and placed into the plastic drum of the Erweka friability tester (GmbH, Type TA 120, D-63150, Heusenstamm, Germany). Upon testing, the drum was attached to the main unit and rotation was conducted at $25 \mathrm{rpm}$. Following 100 revolutions (or $4 \mathrm{~min}$ ), the tablets were removed from the device and cleaned to remove any excess powder or dust. These tablets were then weighed, analysed and compared to the initial weight for any loss, which should not exceed 1\% (BP., 2016b). Equation 4 was used to calculate the percentage friability of tablets:

\section{Equation 4: $\quad$ Percentage Friability $=\left(\frac{w_{1}-W_{2}}{w_{1}}\right) \times 100$}

Where, $W_{1}$ is the initial weight or tablets weight before conducting the friability test

$\mathrm{W}_{2}$ is the weight of tablets measured after testing was completed

\subsection{Scanning Electron Microscopy (SEM)}

Scanning electron microscopy (SEM) is commonly employed to investigate the morphological features of dry particles. In the present study, we used SEM to study the surface morphology of proliposome tablets. Prior to imaging, all samples were air dried on SEM stubs and gold coated with a sputter coater using a JFC-1200 Fine Coater (JEOL, Tokyo, Japan) for 2 min, followed by examination using an SEM instrument (Quanta-200, FEI) at $20 \mathrm{kV}$, and images were taken at various magnifications.

\subsection{Hydration and drug entrapment in liposomes}

Proliposome tablets (10 tablets) were triturated in a mortar using a pestle. The crushed proliposome tablets $(300 \mathrm{mg})$ were subsequently weighed in a glass vial $(25 \mathrm{ml})$ followed by hydration with aqueous solvent $(10 \mathrm{ml})$ to form a liposome suspension $(30 \mathrm{mg} / \mathrm{ml}$, i.e. $30 \mathrm{mg}$ of proliposome powder 
was dispersed in $1 \mathrm{ml}$ of solvent media as a standard ratio). Liposome suspensions were then left for $2 \mathrm{~h}$ at room temperature to anneal before determination of drug entrapment efficiency.

Using deuterium oxide $\left(\mathrm{D}_{2} \mathrm{O}\right)$ as dispersion medium, a separation speed of $13,000 \mathrm{rpm}(15,500 \mathrm{~g})$ and time duration of 90 min using a bench centrifuge (using a Spectrafuge 24D, Jencons-PLS, UK) were applied to separate unentrapped (i.e. sedimented BDP crystals and the dissolved BDP in aqueous media) from liposome-entrapped fraction of the steroid. HPLC (Agilent 1200 HPLC instrument, UK) was used to quantify BDP in different distinct fraction formed (Khan et al., 2015, Khan et al., 2017). Deuterium oxide, also known as heavy water, was used in this study due to its established ability to facilitate the separation of free BDP crystals upon centrifugation based on the fact that steroid crystals have higher density than liposome vesicles; thus, upon centrifugation, the unentrapped drug crystals sedimented while liposome vesicles (incorporating a fraction of BDP) floated at the surface (Batavia et al., 2001, Khan et al., 2015, Khan et al., 2017). Preforming the separation experiments in conventional deionized water results in concomitant sedimentation of both free steroid crystals and liposomes incorporating the drug, justifying the employment of 'heavy water' (Khan et al., 2015, Khan et al., 2017). It is important to bear in mind that the use of the heavy water was confined to the entrapment investigations. BDP was assayed by employing a mixture of 75:25 (v/v) methanol and deionised water as the mobile phase at a flow rate of $1.7 \mathrm{ml} / \mathrm{min}$, and $239 \mathrm{~nm}$ was used as the detection wavelength. The temperature was set and maintained at $40^{\circ} \mathrm{C}$, with an injection volume of $20 \mu \mathrm{l}$. The HPLC column used was a $150 \mathrm{~mm}$ X $4.6 \mathrm{~mm}, \mathrm{C}-18,5$-micron column (Agilent technology, USA).

\subsection{Characterization of sorbitol-based proliposome tablets for stability purposes}

Sorbitol-based proliposome tablets in 1:15 w/w lipid to carrier ratios were selected for stability studies (based on investigation in the results sections). These proliposome tablets were hydrated to generate liposomes followed by characterization in terms of VMD (also referred as size analysis), SPAN (known as size distribution), zeta potential (surface charge), and drug entrapment efficiency. Furthermore, the tablets were checked against the established set of compendial QC tests (i.e. uniformity of weight, disintegration time, hardness and friability). A portion of freshly manufactured batches of sorbitol-based proliposome tablets in 1:15 lipid to carrier were tested and considered as a control (proliposome tablets). The remaining portions of each manufactured tablets batch (each in triplicate) were kept at fridge temperatures $\left(\mathrm{FT} ; 6^{\circ} \mathrm{C}\right)$, room temperature $\left(\mathrm{RT} ; 22^{\circ} \mathrm{C}\right)$ and high temperature $\left(\mathrm{HT} ; 40^{\circ} \mathrm{C}\right)$ for a stability studies over a period of 18 months (i.e. 1, 2, 3, 4, 5, 6, 12 and 18 month).

VMD, also commonly known as median size or $50 \%$ undersize and SPAN (a term introduced by Malvern Instrument software to express the polydispersity of the particles) of liposomes generated from sorbitol-based proliposome tablets in a 1:15 w/w ratio was determined by laser diffraction (Malvern Mastersizer 2000, Malvern Instruments Ltd., UK). Mathematically, SPAN was calculated by the instrument's software; SPAN $=(90 \%$ undersize $-10 \%$ undersize $) / 50 \%$ undersize 
Zetasizer Nanoseries (Malvern Instruments Ltd., UK) automatically calculates the zeta potential of liposomes. Liposome suspensions of $700 \mu \mathrm{l}$ were transferred using a Gilson pipette (Gilson Pipetman, UK) into a cell made from polystyrene latex. The measurement temperature was adjusted at $25^{\circ} \mathrm{C}$, and using Laser Doppler Velocimetry (LDV) the electrophoretic mobility of liposomes in dispersion was analysed.

\subsection{Statistical analysis}

Statistical analysis was performed on the data obtained using one-way analysis of variance (ANOVA) or Student's t-tests by employing the SPSS software, to determine whether the difference is significantly different between more than two groups or two sets of data, respectively. All experiments were conducted in triplicate using three different batches and the level of significance in difference was chosen as $p<0.05$.

\section{RESULTS AND DISCUSSION}

\subsection{Tapped density of proliposome powders}

Out of the coarse carbohydrate carriers investigated, sorbitol exhibited fair flowability (based on Carr's scale of flowability) (Carr, 1965, BP., 2016d), with a compressibility index of $17.06 \pm 0.14 \%$ and a Hausner ratio of $1.21 \pm 0.01$ (Table 1 and Table 2) ( $p<0.05$ ), when compared to D-mannitol, which was comparatively found to exhibit very poor flow properties (i.e. a compressibility index of $34.78 \pm$ $2.03 \%$ and a Hausner ration of $1.53 \pm 0.05$ ) (Table 1 and Table 2).

Coarse carbohydrate carriers were utilised as a control, in order to study the effect of lipid content on the carbohydrate carriers, and subsequently to investigate their influence on proliposome powder flowability for the purpose of tableting. Irrespective of formulation's lipid to carrier ratio (i.e. 1:10 or $1: 15)$, the presence of BDP elicited no effect ( $p>0.05$ ) on powder flow properties, as characterized by Carr's scale of flowability. Consequently, proliposome powder formulations with drug were selected for comparison in the forthcoming discussion.

Overall, the compressibility index and Hausner ratio, both indicated that the 1:10 lipid to carrier ratio formulations possessed a trend for better $(p>0.05)$ flow properties for both carriers; in comparison to formulations at $1: 15 \mathrm{w} / \mathrm{w}$ lipid to carrier ratio. Higher flowability of powder is expected to allow for improved filling of the die; and hence, upon compression, tablet weight uniformity is likely to be improved. In order to further understand the differences in powder flow properties between the formulations studied; the lipid content in each formulation was analysed by the Stewart assay (Stewart, 1980). The assay results confirmed that the $1: 10 \mathrm{w} / \mathrm{w}$ ratio formulations had higher lipid concentrations than the $1: 15 \mathrm{w} / \mathrm{w}$ ratio (Table 3 ), indicating that high lipid incorporation in the slurry resulted in successful coating of the carbohydrate particles. The higher lipid content was deemed to be responsible for causing powder particles to be more coherent, thus increasing resistance to flow 
and preventing adequate compaction during tapping of the proliposome powders. This would explain the lower compressibility index values via tapped density observed for the higher lipid content formulations (i.e. 1:10 lipid to carrier), when compared to proliposomes with lower lipid content (i.e. 1:15 lipid to carrier) (Table 2). The reduction in lipid content in the latter formulation is associated with an increased in void spaces between the particles.

\subsection{Angle of repose of proliposome powder formulations}

On comparison of the investigated formulations, a number of notable differences were observed in terms of angle of repose (AOR). Firstly, it was noted that the incorporation of BDP had insignificantly affected the AOR of the proliposome formulations ( $p>0.05)$, consequently, only BDP containing formulations were discussed in detail.

The AOR values of sorbitol-based BDP incorporated formulations in 1:10 and 1:15 lipid to carrier ratios were $26.61 \pm 0.08^{\circ}$ and $25.62 \pm 1.08^{\circ}$, respectively, and were found to be significantly lower $(p<0.05)$ than $\mathrm{AOR}$ for coarse sorbitol powder $\left(28.33 \pm 0.38^{\circ}\right)$. All values for sorbitol-based proliposome formulations were found to be within the range of $25-30^{\circ}$ (Table 1 and Table 2), indicating 'excellent' flowability. Anh and Kathleen (2001) have reported that particle size of sorbitol is responsible for its flowability and suitability for direct compression. The excellent flowability observed using sorbitol may be therefore attributed to the morphology of the particles. Sorbitol is well noted for being irregular to spherical in shape, identifying it as a carrier with unique flowability.

In addition to its shape, sorbitol particle surfaces are noted to possess protruding needles, owing to its high porosity (Newman et al., 1999, Khan et al., 2017), which may prevent particle agglomeration and provide void spaces. This is potentially due to the ability of these porous structures to accommodate the lipid phase within proliposome formulations, hence stickiness between adjacent particles is minimized (Payne et al., 1986b), resulting in preserved flowability upon coating with lipids (Ahn et al., 1995, Elhissi et al., 2011). Sorbitol-based proliposome formulations at a 1:15 lipid to carrier ratio demonstrated highest flowability $\left(A O R=25.62 \pm 1.08^{\circ}\right)$. Literature findings indicate that powder flowability is highly influenced by size, shape and bulk density of the particles (Liu et al., 2012, Saw et al., 2013, Szalay et al., 2015), agreeing with our AOR studies for sorbitol-based proliposome powder (Table 2).

By contrast, D-mannitol-based proliposome powder exhibited the highest AOR values, ranging from $40.88 \pm 0.56^{\circ}$ and $40.02 \pm 0.51^{\circ}$ for $1: 10$ and $1: 15$ lipid to carrier ratios; to $43.78 \pm 1.30^{\circ}$ for coarse $D$ mannitol. On categorization of these values using Carr's indicator for powder flow properties, Dmannitol demonstrated 'passable' or 'adequate' flowability (Table 2 and Table 1) (Carr, 1965). Again, morphology of the coarse carbohydrate carrier particles was found to be an influential factor on powder flow. The crystalline oblong shape of D-mannitol has been reported to be the reason behind for the compromised flow of this powder (Yan-yu et al., 2006, Khan et al., 2017). 
In addition to particle morphology which is agreed to be a prime factor influencing powder flowability, the lipid content of the proliposome powder formulations was believed to be another influential factor. The reduction in lipid content may cause a trend for decrease in AOR, but that, however, was not significant statistically $(p>0.05)$ (Table 2 and Table 1$)$. As the quantity of carbohydrate carrier is increased in 1:15 lipid to carrier formulation, the lipid may spread more thinly and uniformly over the carrier particles, reducing particle-particle coherence, offering an explanation for the trend of $A O R$ reduction.

The particle size of coarse sorbitol carrier was in the range of $250-700 \mu \mathrm{m}$, whereas the particle size of coarse D-mannitol was $<250 \mu \mathrm{m}$. Sorbitol particles are spherical in terms of shape and thus exhibited better flow properties. Moreover, as the particle size distribution is uniform, this in turn offers minimal weight variation between sorbitol-based proliposome tablets (due to uniform filling of tabletting machine die) (Khan et al., 2017). D-mannitol particles are crystalline/oblong in terms of morphology and irregular in terms of size distribution, thus associated flow properties are poorer (as indicated by high values of angle of repose).

Significant differences $(p<0.05)$ in AOR values were observed between sorbitol and D-mannitol-based proliposome formulations (Table 2). Sorbitol was identified as a more flowable proliposome powder (when compared to D-mannitol-based formulations), which can be expected at this stage of the investigation to produce tablets with more favourable characteristics in terms of appearance, hardness, weight variation and disintegration time. These characteristics represent a prime focus of the subsequent sections.

\subsection{Selection of proliposome powder formulations for tablet manufacturing}

During tablet manufacture, sorbitol-based proliposome powders at the ratio of $1: 10 \mathrm{w} / \mathrm{w}$, and Dmannitol-based proliposome powder in a 1:10 and 1:15 w/w ratio exhibited sticking to the punches and die during tableting. This might be attributed to the higher lipid content in D-mannitol-based proliposome powder (Table 3). The lipid phase forms an amorphous coating over the carbohydrate particles individually to form proliposome powder. Previous reports have shown that during tabletting, higher lipid content (e.g. mineral oil) may reduce interlocking of particles (e.g. weakening particle bonding/deformation) during the tabletting process i.e. there is increased resistance to compaction force with rising the lipid concentration, potentially resulting in a reduction in tablet strength (Moody et al., 1981, Roberts et al., 2004). Hydrophobic additives in tablet formulations (such as magnesium stearate) may also influence the flow and compaction properties at excessively high concentrations; these additives may resist compaction whereas at suboptimal concentrations flow properties are not influenced sufficiently to promote die filling (Roberts et al., 2004, Rana and Kumar, 2013). The lipid coating on the proliposome particles is also hydrophobic, thus when not optimised, may mirror some of the properties discussed (i.e. reducing compaction properties). Hence automated tablet manufacturing with the aforementioned ratios and formulation was not possible. Contrastingly, at a lower lipid concentration (i.e. 1:15 lipid to carrier ratio for sorbitol carrier) (Table 3), the proliposome 
powder did not preclude the automated manufacture of proliposome tablets (i.e. $20 \pm 4$ tablets per min with compression force of $3.00-4.50 \mathrm{kN}$ ), facilitating the manufacture of tablets at this ratio.

Due to stickiness associated with sorbitol-based proliposome in a 1:10 ratio, and D-mannitol-based proliposome formulations for both ratios (i.e. 1:10 and 1:15), the manufacture of tablets from these formulations was conducted manually rather than automatically.

\subsection{Surface morphology characterization of proliposome tablets using SEM}

SEM was employed in this study to examine the surface morphology of the proliposome tablets. Comparisons of BDP-containing and BDP-free tablets had no difference in surface morphology, indicating that BDP did not apparently affect the morphology of tablet surfaces.

Upon SEM examination of sorbitol-based proliposome tablets $(1: 10 \mathrm{w} / \mathrm{w})$, the surface morphology exhibited the presence of fissures (Figure 1a). These were attributed to the higher lipid content which would result in resistance to the compaction force during tabletting. At the $1: 15 \mathrm{w} / \mathrm{w}$ lipid to carrier ratio (Figure 1b), sorbitol-based proliposome tablets elicited lower roughness in terms of fissures on the surface of tablet. The low proportion of lipid to sorbitol carrier in the formulation was also confirmed using the Stewart assay (Table 3). Moreover, tablet surface did not elicit protruding needles of sorbitol when prepared using 1:10 or 1:15 lipid to carrier powder. The reduced lipid content in proliposome particles may have facilitated the compaction of the proliposome powder, without causing stickiness of the particles to the punch surface.

When D-mannitol carrier was used, differences in the surface appearance of the tablets in accordance to using different lipid to carrier ratio was evident (Figure 1c and 1d). D-mannitol-based tablets in 1:10 w/w were found to adhere to the punches and die; this is supported by SEM images which illustrated the presence of crystals and scattered lipid on the D-mannitol tablet surfaces. Dmannitol-based proliposome tablets using the 1:15 lipid to carrier ratio were found to exhibit smoother surfaces (Figure 1d) compared to tablets manufactured using 1:10 ratio (Figure 1c), which is again attributed to the lipid content in the formulation (i.e. lower lipid content resulted in less adherence of proliposome particles to the surfaces of die and punches).

In terms of compaction, SEM illustrated that sorbitol-based proliposome powders demonstrated improved compaction compared to D-mannitol-based proliposome formulations. Examination of tablets indicated that sorbitol particles exhibited higher deformability upon compaction, possibly due to their porous nature. Contrastingly, D-mannitol was deemed to retain (i.e. do not undergo major changes) its crystalline structure upon compaction (Koner et al., 2015). A reduction in lipid content (i.e. $1: 15 \mathrm{w} / \mathrm{w}$ ratio formulations) was proposed to result in smoother proliposome tablets, formed from both sorbitol and D-mannitol-based tablets at the ratio of 1:15 lipid to carrier. Proliposome tablets were manufactured for both ratios and carriers and were further characterized. 


\subsection{Uniformity of weight of proliposome tablets}

Sorbitol-based proliposome tablets were prepared in a weight that was found to be ranging between $90.17 \pm 4.30 \mathrm{mg}$ and $91.97 \pm 2.81 \mathrm{mg}$ for both lipid to carrier ratios (with or without BDP) (Table 4). Similarly, D-mannitol-based proliposome tablets in 1:10 and 1:15 lipid to carrier ratios were prepared (i.e. with or without BDP) in weight that ranged between $91.44 \pm 4.21$ and $92.16 \pm 3.60 \mathrm{mg}$ (Table 4). The tablet weight deviation range was set at $\pm 7.5 \%$ (for the 80 - $250 \mathrm{mg}$ weight range of tablets), with not more than two tablets permitted to deviate from the average weight and none deviating by more than twice that percentage (BP., 2016e). In sorbitol-based proliposome formulations, only two tablets exhibited deviation from the average weight by $\pm 7.5 \%$. Of the two tablets found, each belonged to each respective ratio (i.e. $1: 10$ and $1: 15 \mathrm{w} / \mathrm{w}$ ), falling in the acceptable range according to $\mathrm{BP}$ standards (i.e. no more than two tablets deviating in each batch from the average tablet weight) (BP., 2016e). Thus, both batches of sorbitol-based proliposome tablets were deemed to have passed weight variation testing.

Comparatively, in D-mannitol-based proliposome tablets, four tablets demonstrated a deviation of \pm $7.5 \%$ in weight for the 1:10 w/w D-mannitol formulations (four tablets each of BDP incorporated tablets and BDP free tablets). Contrastingly, only one tablet showed deviation in excess of $\pm 7.5 \%$, for the $1: 15 \mathrm{w} / \mathrm{w}$ D-mannitol tablet formulation (i.e. without BDP). Tablet weight variation within the accepted range (i.e. sorbitol-based proliposome tablets in a 1:10 and 1:15 w/w lipid to carrier ratio), can indicate uniform distribution of lipid during proliposome powder preparation (using the Slurry method). This was also demonstrated by the AOR values for powder flow properties. AOR values for sorbitol-based powders suggested an 'excellent' flow properties for both lipid concentrations (1:10 and 1:15), whilst 'fair' flowability for D-mannitol-based proliposome powders was observed (Table 2 and Table 1).

\subsection{Disintegration test of proliposome tablets}

Sorbitol tablets manufactured from proliposome powders in a 1:10 lipid to carrier (with or without $\mathrm{BDP}$ ), exhibited an average disintegration time of $8.67 \pm 0.88 \mathrm{~min}$ and $10.04 \pm 0.73 \mathrm{~min}$, respectively (Figure 2a). Similarly, sorbitol-based tablets with 1:15 lipid to carrier ratio showed no significant difference $(p>0.05)$ between formulations containing BDP (i.e. disintegration time was $5.85 \pm 0.66$ $\mathrm{min}$ ), and those without BDP (i.e. disintegration time was $6.15 \pm 0.48 \mathrm{~min}$ ) (Figure 2a). This indicated that, when sorbitol carrier was used, the presence of BDP did not significantly affect the disintegration time of the tablets for each lipid to carrier ratio investigated.

On comparison of sorbitol-based proliposome tablets made from 1:10 and 1:15 lipid to carrier ratios, a statistically significant difference $(p<0.05)$ was observed, with shorter disintegration time noted for the latter formulation. As lipid content is the sole varying factor for each carrier type, it is suggested that lipid content is the only parameter that may affect the disintegration time. Higher lipid content may produce proliposome tablets with higher surface hydrophobicity, which may resist water penetration and prolong the time needed for complete tablet disintegration (Uzunovic and Vranic, 2007). 
Moreover, a significant difference $(p<0.05)$ was observed in the disintegration time for $D$-mannitol formulations, exhibiting a higher disintegration time of $13.60 \pm 0.45 \mathrm{~min}$ for 1:10 formulations when compared to $10.53 \pm 1.16$ min for $1: 15$ formulations (Figure $2 a$ ). This further confirmed that high lipid content was the major influential factor at extending the disintegration time of proliposome tablets.

Surface characteristics (SEM in Figure 1) may correlate with tablet disintegration characteristics, as the surface morphology heavily influences the behaviour of proliposome tablets in a given dispersion medium. The higher lipid content in the $1: 10 \mathrm{w} / \mathrm{w}$ ratio offers an explanation behind the extended disintegration time of the tablet, compared to those manufactured using the 1:15 lipid to carrier. Moreover, upon direct comparison between both carriers, a significant difference was observed in terms of disintegration time $(p<0.05)$, suggesting that carrier selection also plays a pivotal role in the disintegration time of proliposome tablets (Ohrem et al., 2014).

In summary, sorbitol was found to be the superior carrier for proliposome tableting, particularly upon using lower lipid content (i.e. at a ratio of 1:15 lipid to carrier). It was observed by Zhao and Augsburger (2005) that after fragmentation of a tablets in general, tablets allow a quick release of a drug and subsequent bioavailability.

\subsection{Hardness testing (Crushing strength) of proliposome tablets}

Sorbitol-based proliposome tablets made from 1:15 lipid to carrier (with or without BDP), showed a trend of higher, yet statistically insignificant $(p>0.05)$ crushing strength; when compared to proliposome tablets made from the $1: 10 \mathrm{w} / \mathrm{w}$ ratio formulations (Table 4). D-mannitol-based proliposome tablets at both ratios (1:10 and 1:15), were unable to withstand the crushing strength of the hardness tester, showing poor hardness. This may be associated with the fact that coarse mannitol powder has low compressibility (Mizumoto et al., 2005). Moreover, despite the poor hardness exhibited by D-Mannitol-based proliposome tablets, they presented longer disintegration times (Figure 2a), when compared to sorbitol-based proliposome tablets, indicating softness of the Dmannitol-made tablets and poor penetration of water through these compacted particles. D-mannitol D-mannitol particles were observed to be oblong/ellipse in shape (Khan et al., 2017) and therefore resisting compaction (i.e. retained crystallinity), giving rise to low tablet hardness. A similar compression force was employed for sorbitol formulations which conversely exhibited high compactability (i.e. due to high particle deformability) giving rise to high hardness values (Koner et al., 2015). Difference in hardness may suggest that the compression force has changed the sorbitol particles plastically, whereas the D-mannitol particles retained their shape with some fragmentation during compression in the presence of lipid in the formulations. Whilst both formulations exhibited differences in terms of compaction, disintegration times, both were within the acceptable limits (BP., 2016a). Differences observed in disintegration time may further be attributed to carrier solubility. Dmannitol tablets exhibited poor hardness, thus tablets disintegrated relatively $\sim 15$ min disintegration time. Contrastingly, although sorbitol-based tablets exhibited high hardness, its water solubility (2350 $\mathrm{mg} / \mathrm{ml}$ ) is circa 20 fold greater than D-mannitol $(100 \mathrm{mg} / \mathrm{ml})$ (Section 2.1), resulting in a similar 
disintegration time ( 10 min) i.e. in D-mannitol formulations poor hardness was the overriding factor for short disintegration times; and in sorbitol formulations, its exceptionally high water solubility was responsible for a short disintegration time despite high tablet hardness.

Literature findings indicate that the porosity of sorbitol particles may facilitate their ability to pack well upon compression due to their high moulding properties (Sastry et al., 2000, Mizumoto et al., 2005), coming in agreement with the findings in our study using sorbitol-based proliposome tablets.

\subsection{Friability studies}

Upon analysis, sorbitol-based proliposome tablets (BDP incorporated) demonstrated a significantly $(p<0.05)$ lower friability $(0.17-0.19 \%)$, when compared to $D$-mannitol-based proliposome tablets $(0.24-0.42 \%)$ (i.e. irrespective of the lipid to carrier ratio) (Figure $2 b$ ). Additionally, tablets produced from sorbitol-based proliposome powders were found to be harder than D-mannitol-based tablets (Figure 2b). This may be attributed to the ability of sorbitol-based particles to deform more readily upon compaction, due to their porous nature (Khan et al., 2017). Tablets possessing high levels of hardness are known to exhibit lower friability (Desai et al., 2014), which came in agreement with our proliposome tablet findings (Table 4).

Differences between sorbitol-based proliposome tablets at lipid to carrier ratios of 1:10 and 1:15 were found to be statistically insignificant ( $p>0.05$ ), showing friability values of $0.17 \pm 0.03 \%$ and $0.19 \pm$ $0.06 \%$ for the $1: 10 \mathrm{w} / \mathrm{w}$ ratio formulation (with and without BDP respectively); and values of $0.20 \pm$ $0.03 \%$ and $0.19 \pm 0.05 \%$ in the $1: 15$ lipid to carrier tablets (with and without BDP respectively). Dmannitol-based Proliposome tablets (Table 4), were found not to be able to withstand the force applied by the hardness tester, yet still exhibiting a longer disintegration time and greater friability than sorbitol-based proliposome tablets (Figure 2a and 2b).

A significant difference $(p<0.05)$ was found in terms of friability for $D$-mannitol-based proliposome tablets at a 1:10 lipid to carrier, when BDP was incorporated or omitted (i.e. $0.42 \pm 0.04 \%$ and $0.24 \pm$ $0.04 \%)$, showing higher friability for tablets containing BDP. By contrast, upon using the lower lipid content tablets (i.e. 1:15 lipid to carrier), only an insignificant trend $(p>0.05)$ of higher friability in BDPcontaining tablets was observed $(0.37 \pm 0.07 \%$ with BDP and $0.3 \pm 0.09 \%$ without BDP), indicating that the steroid would make the tablets more friable only when high lipid concentration in proliposome powders are used.

Overall, the crushing strength of conventional tablets is directly proportional to the force of compaction used. Additionally, excessive force of compaction may not further increase the tablet hardness, in contrary, it may even result in promoting tablet friability (Perioli et al., 2008). However, higher friability in D-mannitol-based proliposome tablets in lipid to carrier ratios investigated, can possibly be attributed to the tendency of D-mannitol to retain (do not undergo major changes) its crystalline shape (Koner et al., 2015). Additionally, D-mannitol crystals were also found on the tablet surface, suggesting fragility of the tablets (Figure 1c). 
In summary, on investigation of tablet friability, tablets prepared from sorbitol-based proliposomes showed the lowest loss during friability testing, particularly when using 1:15 w/w lipid to carrier ratio.

\subsection{Entrapment efficiency of BDP in liposomes generated from proliposome tablets}

Liposomes generated via hydration (Section 2.12) from sorbitol-based proliposome tablets with 1:10 and 1:15 lipid to carrier ratios, exhibited drug entrapment efficiencies of $53.82 \pm 6.42 \%$ and $57.43 \pm$ $9.12 \%$, respectively. Hence, steroid entrapment efficiencies in liposomes generated from sorbitolbased proliposome tablets were independent of lipid to carrier ratio $(p>0.05)$ (Figure 3). Similarly, lipid to carrier ratio did not affect BDP entrapment by vesicles generated from D-mannitol-based proliposome tablets $(p>0.05)$, being $39.90 \pm 4.30 \%$ and $35.22 \pm 6.50 \%$ for $1: 10$ and $1: 15$ lipid to carrier formulations, respectively. Furthermore, no significant difference $(p>0.05)$ was also found with respect to un-entrapped BDP (i.e. free BDP crystal sedimented and dissolved BDP in aqueous media, post centrifugation) (Khan et al., 2015, Subramanian et al., 2016, Khan et al., 2017). Upon comparison, no significant difference was found for the un-entrapped BDP for sorbitol-based proliposome tablets in both $1: 10$ and 1:15 lipid to carrier ratios (46.18 $\pm 7.29 \%$ and $42.58 \pm 8.77 \%)$. A similar trend was observed for the D-mannitol-based proliposome tablets at the 1:10 and 1:15 lipid to carrier ratios, in terms of un-entrapped BDP $(60.11 \pm 4.46 \%$ and $64.78 \pm 7.35 \%)$ (Figure 3).

Upon comparison of sorbitol and D-mannitol-based proliposome tablets; entrapment efficiency was found to be greater for sorbitol-based tablet formulations. In addition, both 1:10 and 1:15 formulation ratios prepared from sorbitol-based tablets exhibited a significantly $(p<0.05)$ high entrapment of BDP when compared to D-mannitol-based formulation ratios. The higher entrapment efficiency may be explained by the porous nature of sorbitol (Khan et al., 2017), which allows uptake of the lipid constituents into the larger surface area offered by void spaces of the sorbitol particles. As it is mentioned, the entrapment efficiency is associated with the porous structures of the carrier. What is meant by this is that to our understanding, there is a difference in final lipid concentration following tabletting, which in turn influences the final entrapment efficiency. As mentioned (Figure 1), due to its structure, sorbitol may retain lipid content within the porous structure of the carrier during tabletting, thus lipid is accommodated within the porous structures of the carrier during compaction. Contrastingly, D-mannitol's crystalline shape and lack of porosity means that surface lipid concentration prior to tabletting is high and an amount of the lipid is lost by sticking to the die and punch of the tablet press, which is indicated by tablet picking (Figure 1). This reduction in lipid content using D-mannitol means there is less lipid available in the D-mannitol-based proliposome tablets to facilitate drug entrapment, resulting in lower entrapment efficiencies. Thus, sorbitol is identified as a highly appropriate carbohydrate carrier for manufacturing proliposome tablets. 


\subsection{Stability studies of proliposome tablets}

Based on the aforementioned results and discussion, sorbitol-based proliposome tablets in 1:15 ratio were selected for stability studies over a period of 18 months. Sorbitol-based proliposome tablets appeared to be white in colour upon manufacture, and the lipid phase looked uniformly distributed over the particles (Figure 4a). After 18 months of storage of tablets at FT temperature, the white colour of the tablets did not apparently change (Figure 4b). Contrastingly, the colour of sorbitol-based proliposome tablets stored at RT temperature changed to light yellow (Figure 4c), which commonly indicates phospholipid oxidation; this yellowish appearance was more prominent when tablets were stored under HT conditions (Figure 4d). Manjula et al. (2014) reported a discoloration of proliposome powder (prepared using a traditional method) after 90 days, when proliposome powder was kept at $45^{\circ} \mathrm{C}$. Slurry-based proliposome tablets behaved similarly in response to using high temperature.

\subsection{Liposome size and size distribution during stability studies}

Upon direct comparison between various temperature conditions and also in comparison to control tablets (when proliposome tablets were freshly prepared), a significant increase in size (expressed as volume median diameter; VMD) was observed for liposomes (generated upon hydration of sorbitolbased proliposome tablets), when the duration of stability period was extended to 18 months (Figure 5a). At FT, the VMD of liposomes increased from $5.97 \pm 0.38 \mu \mathrm{m}$ (month 1) to $7.13 \pm 0.99 \mu \mathrm{m}$ (18 month). No significant difference ( $p>0.05$ ) was found for VMD between each month upon comparison with the control sample (i.e. $5.90 \pm 0.70 \mu \mathrm{m}$ ), however only a trend for increase in liposome size was observed due to temperature difference. By contrast, when tablets were kept at RT, VMD of liposomes significantly increased $(p<0.05)$ from $5.90 \pm 0.70 \mu \mathrm{m}$ (i.e. for control sample) to $8.45 \pm 0.59$ and $11.98 \pm 0.57 \mu \mathrm{m}$ for 12 and 18 month, indicating vesicle aggregation and / or fusion upon hydration. Moreover, upon direct comparison of VMD of liposomes between RT and FT, size of liposomes stored at RT was found to be significantly larger than that measured for tablets stored at FT for month 6, 12 and 18 (Figure 5a). Liposomes hydrated from sorbitol-based proliposome tablets stored at $\mathrm{HT}$ (i.e. in 1:15 w/w ratio), exhibited a consistent increase in VMD from month 4 throughout to month 18. Thus, the VMD reached $14.79 \pm 0.79 \mu \mathrm{m}$ at month 18 (VMD for control sample was 5.90 $\pm 0.70 \mu \mathrm{m})$.

Storage at HT was suggested to be responsible for the discoloration of proliposome tablets (Figure 4), because of possible degradation of the lipid component via oxidation (Torchilin and Weissig, 2003). Phospholipid degradation at elevated temperature using proliposome powder has been documented in previous research, corroborating findings of our present report (Manjula et al., 2014, Prasad et al., 2014).

SPAN of liposomes generated from the control tablets were compared with liposomes generated from each of the monthly set of tablets for the 18 month stability period (Figure $5 b$ ). Upon analysis of the SPAN values generated from formulations stored at FT, no significant difference $(p>0.05)$ was noted 
for any of the stored samples when direct comparison was made with the control sample $(3.14 \pm 0.55)$ (Figure $5 b)$. Similarly, no significant difference $(p>0.05)$ in SPAN values was exhibited by RT stored formulations, when compared to the control sample. Contrastingly, a significant increase $(p<0.05)$ in SPAN values were observed at $\mathrm{HT}$ for months: $5,6,12$ and 18 (4.32 $\pm 0.29,4.85 \pm 0.86,5.15 \pm 0.78$ and $5.28 \pm 0.56$ ), when compared to the SPAN values of control sample (3.14 \pm 0.55$)$ (Figure $5 b$ ). However, towards the latter months of stability period, SPAN was observed to notably increase in the HT conditions (Figure $5 b)$, i.e. exhibiting a statistically significant difference $(p<0.05)$ when compared to SPAN values of FT and RT stored formulations. High SPAN measurements commonly indicate particle aggregation. Previous research has indicated that high temperature and physical instability (of lipid component) may cause liposome fusion or aggregation, resulting in larger liposomes as well as potential degradation of the concentric bilayers in liposomes (Lasic, 1998, Jain, 2012). This phenomenon (degradation and increased VMD and SPAN) was clearly illustrated by the extended stability studies in figure 5a. Phospholipid integrity was kept to a maximum when samples were stored at FT.

\subsection{Zeta potential of liposomes during stability studies}

For gaining knowledge on the surface properties of liposome vesicles generated upon hydration of proliposome tablets, we conducted a zeta potential analysis on the vesicles, using the same storage protocol employed in the previous section. For tablets stored at FT conditions, a statistically significant difference $(p<0.05)$ was observed when comparing the samples stored at month 6,12 and 18 (i.e. $3.99 \pm 0.25,-5.45 \pm 0.19$ and $-6.22 \pm 0.15 \mathrm{mV}$, respectively) with the control sample $(-3.08 \pm 0.26 \mathrm{mV})$ (Figure $5 \mathrm{c}$ ). A general trend of increase in the negativity of zeta potential values with storage time was found; this increase was substantially higher in the latter months of stability testing. With respect to samples stored at RT, differences $(p<0.05)$ were observed between the control sample $(-3.08 \pm 0.26$ $\mathrm{mV})$ and samples from months 5, 6, 12 and $18(-4.00 \pm 0.22,-6.31 \pm 0.27,-7.03 \pm 0.29$ and $-8.47 \pm$ $0.18 \mathrm{mV}$ ), exhibiting higher zeta potential values than control sample (Figure $5 \mathrm{c}$ ). Additionally, measurements conducted in months 5, 6, 12 and 18 (i.e. for RT) were found to be significantly higher $(p<0.05)$ to the alternate months tested (i.e. 1, 2, 3 and 4$)$; these values of zeta potential (i.e. months $5,6,12$ and 18 at RT) were also higher when compared to the samples stored at FT (i.e. for the same months of 5, 6, 12 and 18). Again a raised zeta potential was observed for the latter months, which possibly indicates that under the RT storage conditions the lipid component is stable for the initial four month storage period (Figure $5 c$ ).

Proliposome tablets stored under HT (after hydration into liposome suspension) were found to exhibit a stronger trend in terms of increasing zeta potential in comparison to the control sample, as well as to the samples stored in FT and RT. Initially, a statistically significant difference $(p<0.05)$ was noted between the control sample $(-3.08 \pm 0.26 \mathrm{mV})$ and samples from months $3,4,5,6,12$ and $18(-4.52 \pm$ $0.17,-6.39 \pm 0.40,-6.84 \pm 0.13,-7.93 \pm 0.25,-8.68 \pm 0.31$ and $-11.97 \pm 0.26 \mathrm{mV}$ respectively) showed a higher zeta potential under HT storage condition (Figure 5c). Similarly, higher zeta potential values 
were also found for the same months (i.e. 3, 4, 5, 6, 12 and 18) to the zeta potential of both samples stored at FT as well as RT $(p<0.05)$.

Overall, irrespective of the storage conditions, zeta potential was found to increase over time, this was observed to be more drastic following the third month of storage at $\mathrm{HT}$, and sixth month of storage for RT and FT. Linked with the discolouration of tablets (Figure 4), this further supports the suggestion that lipid component has degraded with time. Oxidation of double bonds (catalysed by metal impurities) of the hydrocarbon chain present in lipid molecules may be accelerated by heat and light, producing free radicals (Klemchuk, 2000). The addition of an oxygen molecule usually occurs at a carbon next to a double bond producing hydroperoxides, which are not stable and therefore decompose into aldehydes or carboxylic acids (also cause rancidity) (Frankel, 2005, Gueraud et al., 2010). Deprotonation of these carboxylic acids (i.e. removal of $\mathrm{H}^{+}$) results in the formation $\mathrm{O}^{-}$groups, increasing overall negative charge. Moreover, hydrolysis of fatty acids and sugars (e.g. disaccharides) may occur at both acidic and basic $\mathrm{pH}$, this process is further supported by the presence of impurities (e.g. metal ions) which can cause an increase in polar units (Burgess, 1978, Richens, 1997). The unsaturated bonds in the presence of heat, may facilitate oxidation and the conversion of double bonds into hydroxyl groups in the hydrocarbon chain (Klemchuk, 2000). The presence of alkaline $\mathrm{pH}$ may further cause deprotonation, again increasing negative charge. SPC (i.e. phospholipid) employed in the formulation was of $94 \%$ purity (Section 2.1 ), the unaccounted $6 \%$ of the formulation may be comprised of metal ions and other substances which may impact the aforementioned processes.

Further studies would attempt to identify the cause of lipid degradation; a potential cause may be oxidation of the lipid components resulting in discoloration under HT storage conditions (Torchilin and Weissig, 2003).

\subsection{Proliposome tablets characterization during storage}

Comparisons in terms of weight uniformity, disintegration time, crushing strength and friability of tablets were made between each month (under each set of storage conditions i.e. FT, RT and HT) for the entire 18 month duration, as well as with a control batch of tablets.

Upon direct comparison of the control sample with each month sample at each condition (i.e. FT, RT and HT), no significant difference ( $p>0.05)$ was observed in terms of weight variation, hardness and friability between the batches (Table 5 ). This indicated that weight and strength of tablets remained relatively constant and stable irrespective of the storage time or temperature. In disintegration testing, upon examination of the FT stored samples at various monthly intervals, no significant difference ( $p>0.05$ ) was found between the control sample and any of the monthly tested sample stored at FT. The same results were found for tablets stored at RT condition, with only exception of 18 month, exhibiting lower disintegration time of $3.97 \pm 0.32$ min compared to the control proliposome tablets (5.85 $\pm 0.66 \mathrm{~min}$ ) (Table 5). Upon comparison of HT stored tablets, a statistically significant difference $(p<0.05)$ was found between samples tested at months 6,12 and $18(3.79 \pm 0.55,3.46 \pm 0.63$ and 
$3.06 \pm 0.71 \mathrm{~min})$ exhibited lower disintegration time than the control sample $(5.85 \pm 0.66 \mathrm{~min})$ (Table $5)$.

The variance in disintegration time over an extended period, suggests that disintegration time is not stable throughout storage under HT conditions, particularly for the latter months. However, it is noteworthy that the degree of change in time is relative, and the disintegration conforms well with $\mathrm{BP}$ guidelines for uncoated standard tablets, even though it has seen to decrease over time (Table 5). Shorter disintegration time in traditional contexts is not perceived as a disadvantage; however at the present investigation where materials liable to degradation such as phospholipids are incorporated, the rapid disintegration indicates a change in the chemical structure or physical form of the tablet constituents, supporting the earlier size and zeta potential findings.

Potentially, storage at the elevated temperature may also affect the lipid content on the proliposome tablets, resulting in decreased disintegration time. This may be attributed to the degradation of the lipid component, which in turn may reduce the hydrophobicity of the tablet, hence reduce disintegration time.

\subsection{Entrapment efficiency of BDP during stability}

Entrapment efficiency was investigated earlier in section 3.9 in order to determine the proportion of drug that is available to provide a gradual release from the vesicles. It is important also to study whether various storage temperatures can affect the proportion of steroid that will be entrapped upon hydration of the tablets. No significant difference $(p>0.05)$ in entrapment efficiency was observed upon comparing of the FT stored formulations for six months with the control sample, indicating that entrapment at this temperature did not compromise the amount of drug that is available to provide controlled release. However, the entrapment significantly $(p<0.05)$ decreased to $41.18 \pm 4.96$ and $38.66 \pm 3.09 \%$ for 12 and 18 month to the control sample $(57.43 \pm 9.12 \%$ ) (Figure $5 \mathrm{~d}$ ); this trend was mirrored by RT stored samples. Again, the entrapment of BDP decreased to $42.14 \pm 5.18$ and $34.68 \pm$ $2.58 \%$ for 12 and 18 month when compared to the control tablets (57.43 $\pm 9.12 \%$ ) (Figure $5 d$ ). This indicated that proliposome tablets stored at FT and RT retained good stability for six months in terms of entrapment efficiency, but the extended stability period (i.e. after six months) resulted in a reduction in entrapment of BDP. Proliposome tablets stored under HT conditions, exhibited a significant difference in entrapment efficiency of BDP after three months to the entrapment efficiency demonstrated by the control sample. A significant $(p<0.05)$ drop in entrapment was observed for the latter months for tablets stored at HT conditions. The entrapment efficiency gradually reduced from $57.43 \pm 9.12 \%$ of the control sample to $32.56 \pm 5.47,32.03 \pm 4.57,29.30 \pm 3.63,25.13 \pm 6.22$ and $17.93 \pm 5.37 \%$ respectively, for months $4,5,6,12$ and 18 (Figure $5 \mathrm{~d}$ ). This trend of lower entrapment was also exhibited by the sample stored at HT storage conditions to the tablets stored at FT as well as RT. Moreover, BDP exhibited a retention time of $3.76 \mathrm{~min}$ for all the sample investigated (i.e. for control sample as well as sample stored for 18 months at different temperature conditions). 
The lower entrapment values obtained for the FT, RT (after 6 months) and HT stored samples at month 4, 5, 6, 12 and 18 may be explained by potential degradation of the lipid over storage condition for extended period of time. Potential degradation in the lipid may subsequently resulted in a lower concentration of liposome generation in the dispersion medium and as a consequence, a lower entrapment efficiency of BDP achieved. This is supported by Gupta et al., (2008) using proliposome powders, who reported that lower lipid concentrations would result in lower entrapment efficiencies (Gupta et al., 2008). Moreover, temperature above the phase transition temperature of the lipid is believed to cause destabilization in the lipid content, resulting in drug leakage from the liposome vesicles and consequently lower the entrapment efficiency (Lasic, 1998). Another study conducted by Kurakula et al., (2012) utilising prednisolone in proliposome powder formulations manufactured using particulate-based proliposome method, exhibited that samples stored at elevated temperatures as well as low temperatures (i.e. freezing) were found to insignificantly ( $p>0.05)$ affect the entrapment efficiency, for up to a period of three months (Kurakula et al., 2012), agreeing with our findings (for a period of three months). However, this research has conducted stability testing for a period of 18 months, as opposed to 3 months, and we showed a significant drop in stability following 3 months storage (HT storage conditions).

In an additional study where proliposome powder formulations were stored at varied temperatures (i.e. $8,25,37$ and $45^{\circ} \mathrm{C}$ ) for 90 days (Manjula et al., 2014), it was observed that following 90 days, proliposome powders stored at 8 and $25^{\circ} \mathrm{C}$ were stable in terms of physical appearance (e.g. colour) and also the entrapment of the incorporated drug Fenoprofen. Notably, proliposome colour changed and the entrapment efficiency dropped by $12 \%$ at the third month for the sample stored at $45^{\circ} \mathrm{C}$. Elevated temperature may be responsible for lipid degradation (Manjula et al., 2014). In the present research, the change in colour of the sorbitol-based proliposome tablets was observed at month 6 and onwards (clear discoloration for tablets stored at HT, less discoloration for RT and minor discoloration for FT), this may potentially indicate degradation in the lipid component, which is also supported by lower entrapment values at 6 months (Figure $5 \mathrm{~d}$ ). In another study, proliposome powders formulated with naproxen, storage at $40^{\circ} \mathrm{C}$ for three months resulted in a reduction of entrapment efficiency, further highlighting the deleterious effect of elevated temperatures on proliposome formulations. In that study, it was proposed that drug leakage at the elevated temperature was responsible for the lower entrapment values observed, and that storage at $8^{\circ} \mathrm{C}$ may minimized this effect (Prasad et al., 2014).

Our investigation is the first one of its kind that utilized proliposomes prepared using a slurry approach to manufacture tablets that were thoroughly characterized and subjected to a prolonged stability study at various temperatures. The forthcoming publications will be on the delivery options of proliposome tablets using steroids and possibly other drugs.

\section{CONCLUSIONS}


Sorbitol was identified as the most appropriate carbohydrate carrier for proliposome powder formulation, when used in a 1:15 w/w lipid to carrier ratio, due to its excellent proliposome powder flowability as confirmed by angle of repose, compressibility index and Hausner ratio studies. High entrapment efficiency was elicited by the sorbitol-based proliposome tablets with the 1:15 w/w lipid to carrier ratio. Sorbitol-based proliposome tablets also had surface characteristics that made them able to readily accommodate the lipid phase. Furthermore, the lower friability, shorter disintegration time and higher drug entrapment efficiency offered by sorbitol-based proliposomes made them more promising than their D-mannitol formulation counterparts. Overall, it was concluded that sorbitolbased proliposome tablets manufactured via 1:15 lipid to carrier ratio complied with all quality control tests employed in this study. Stability testing at three different temperatures over a prolonged period of 18 months resulted in marginal increases in VMD and zeta potential; contrastingly, entrapment efficiency of BDP was dramatically decreased at the latter months, a change more evident in HT stored tablets. FT conditions were found to enhance stability with extended storage time and storage condition exhibiting no significant effect upon the standards offered by BP. Importantly, these "proliposome tablets" were the only formulation that were allowed manufacture using the automated function (20 \pm 4 tablets per min with compression force of $3.00-4.50 \mathrm{kN}$ ) of the Minipress machine; thus providing scope for large scale industrial manufacture of proliposome tablets, which can be hydrated before use. This study will take further dimensions in the future to explore the drug delivery applications using proliposome tablets.

\section{Acknowledgment}

We are very thankful to Lipoid, Switzerland for their generous supply of phosphatidylcholine (SPC, Lipoid S-100).

\section{References}

AHN, B.-N., KIM, S.-K. \& SHIM, C.-K. 1995. Preparation and evaluation of proliposomes containing propranolol hydrochloride. J Microencapsul, 12, 363-375.

ANH, S. L. \& KATHLEEN, B. M. 2001. Sorbitol and Mannitol. In: NABORS, L. B. (ed.) Alternative Sweeteners. Marcel Dekker, Inc. USA, 3, 317-334.

BATAVIA, R., TAYLOR, K. M. G., CRAIG, D. Q. M. \& THOMAS, M. 2001. The measurement of beclomethasone dipropionate entrapment in liposomes: a comparison of a microscope and an HPLC method. International Journal of Pharmaceutics, 212, 109-119.

BP. 2016a. Disintegration. Disintegration of Tablets and Capsules. London, UK: Stationary Office on behalf of MHRA.

BP. 2016b. Friability. London, UK: Stationary Office on behalf of MHRA.

BP. 2016c. Powder Flow. Angle of Repose. London, UK: Stationary Office on behalf of MHRA.

BP. 2016d. Powder Flow. Bulk Density and Tapped Density of Powder. London, UK: Stationary Office on behalf of MHRA.

BP. 2016e. Uniformity of Weight (Mass). London, UK: Stationary Office on behalf of MHRA.

BURGESS, J. 1978. Metal lons in Solution New York, USA, Ellis Horwood Ltd.

CARR, R. 1965. Evaluating flow properties of solids. Chem. Eng., 72, 163-168. 
DESAI, P. M., ER, P. X., LIEW, C. V. \& HENG, P. W. 2014. Functionality of disintegrants and their mixtures in enabling fast disintegration of tablets by a quality by design approach. AAPS PharmSciTech, 15, 1093104.

ELHISSI, A. M. A., AHMED, W., MCCARTHY, D. \& TAYLOR, K. M. G. 2011. A Study of Size, Microscopic Morphology, and Dispersion Mechanism of Structures Generated on Hydration of Proliposomes. Journal of Dispersion Science and Technology, 33, 1121-1126.

EPA. 2013. Particulate matter [Online]. USA: Environmental Protection Agency. Available: http://www.epa.gov/airscience/air-particulatematter.htm [Accessed 10.01.2013].

FRANKEL, E. N. 2005. Lipid Oxidation, Philadelphia, USA, Oily Press.

GUERAUD, F., ATALAY, M., BRESGEN, N., CIPAK, A., ECKL, P. M., HUC, L., JOUANIN, I., SIEMS, W. \& UCHIDA, K. 2010. Chemistry and biochemistry of lipid peroxidation products. Free Radic Res, 44, 1098-124.

GUPTA, V., BARUPAL, A. K. \& RAMTEKE, S. 2008. Formulation Development and in vitro Characterization of Proliposomes for Topical Delivery of Aceclofenac. Indian J Pharm Sci, 70, 768-75.

HUNT, C. A. \& TSANG, S. 1981. $\alpha$-Tocopherol retards autoxidation and prolongs the shelf-life of liposomes. International Journal of Pharmaceutics, 8, 101-110.

JAIN, M. 2012. Development of Liposome Drug Delivery Systems for Anti-Glioma Therapy. MSc by Research MSc by Research, University of Central Lancashire.

JIVRAJ, I. I., MARTINI, L. G. \& THOMSON, C. M. 2000. An overview of the different excipients useful for the direct compression of tablets. Pharm Sci Technolo Today, 3, 58-63.

KHAN, I., ELHISSI, A., SHAH, M., ALHNAN, M. A. \& WAQAR, A. 2013. Liposome-based carrier systems and devices used for pulmonary drug delivery. In: DAVIM, J. P. (ed.) Biomaterial and medical tribology research and development. Cambridge, UK: Woodhead Publishing Limited.

KHAN, I., YOUSAF, S., ALHNAN, M. A., AHMED, W., ELHISSI, A. \& JACKSON, M. J. 2016. Design Characteristics of Inhaler Devices Used for Pulmonary Delivery of Medical Aerosols. In: AHMED, W. \& JACKSON, M. J. (eds.) Surgical Tools and Medical Devices. Cham: Springer International Publishing.

KHAN, I., YOUSAF, S., SUBRAMANIAN, S., ALHNAN, M. A., AHMED, W. \& ELHISSI, A. 2017. Proliposome Powders for the Generation of Liposomes: the Influence of Carbohydrate Carrier and Separation Conditions on Crystallinity and Entrapment of a Model Antiasthma Steroid. AAPS PharmSciTech.

KHAN, I., YOUSAF, S., SUBRAMANIAN, S., KORALE, O., ALHNAN, M. A., AHMED, W., TAYLOR, K. M. G. \& ELHISSI, A. 2015. Proliposome powders prepared using a slurry method for the generation of beclometasone dipropionate liposomes. International Journal of Pharmaceutics, 496, 342-350.

KLEMCHUK, P. P. 2000. Antioxidants. Ullmann's Encyclopedia of Industrial Chemistry. Wiley-VCH Verlag GmbH \& Co. KGaA.

KONER, J. S., RAJABI-SIAHBOOMI, A., BOWEN, J., PERRIE, Y., KIRBY, D. \& MOHAMMED, A. R. 2015. A Holistic Multi Evidence Approach to Study the Fragmentation Behaviour of Crystalline Mannitol. Scientific Report, 5, 1-12.

KURAKULA, M., SRINIVAS, C., KASTURI, N. \& DIWAN, P. V. 2012. Formulation and Evaluation of Prednisolone Proliposomal Gel for Effective Topical Pharmacotherapy. Inter J Pharm Sci \& Drug Research, 4, 35-43.

LASIC, D. D. 1998. Novel applications of liposomes. Trends Biotechnol, 16, 307-21.

LIU, L. X., RASHID, A., MARZIANO, I., WHITE, E. T., HOWES, T. \& LITSTER, J. D. 2012. Flowability of binary mixtures of commercial and reprocessed ibuprofen through high shear wet milling (HSWM) with lactose. Advanced Powder Technology, 23, 454-458.

MANJULA, D., SHABARAYA, A. \& SOMASHEKAR, S. 2014. Topical Delivery of Fenoprofen Proliposomes: Preparation, Evaluation and In Vitro Release. International Journal of Pharmaceutical Science Invention, 3, 6-12.

MIZUMOTO, T., MASUDA, Y., YAMAMOTO, T., YONEMOCHI, E. \& TERADA, K. 2005. Formulation design of a novel fast-disintegrating tablet. International Journal of Pharmaceutics, 306, 83-90.

MOODY, G., RUBINSTEIN, M. H. \& FITZSIMMONS, R. A. 1981. Tablet lubricants I. Theory and modes of action. International Journal of Pharmaceutics, 9, 75-80.

NEWMAN, A. W., VITEZ, I. M., MUELLER, R. L., KIESNOWSKI, C. C., FINDLAY, W. P., RODRIGUEZ, C., DAVIDOVICH, M. \& MCGEORGE, G. 1999. Sorbitol. In: HARRY, G. B. (ed.) Analytical Profiles of Drug Substances and Excipients. Academic Press.

OHREM, H. L., SCHORNICK, E., KALIVODA, A. \& OGNIBENE, R. 2014. Why is mannitol becoming more and more popular as a pharmaceutical excipient in solid dosage forms? Pharm Dev Technol, 19, 257-62.

PAYNE, N. I., BROWNING, I. \& HYNES, C. A. 1986a. Characterization of proliposomes. Journal of Pharmaceutical Sciences, 75, 330-333. 
PAYNE, N. I., TIMMINS, P., AMBROSE, C. V., WARD, M. D. \& RIDGWAY, F. 1986b. Proliposomes: a novel solution to an old problem. J Pharm Sci, 75, 325-9.

PERIOLI, L., AMBROGI, V., GIOVAGNOLI, S., BLASI, P., MANCINI, A., RICCI, M. \& ROSSI, C. 2008. Influence of compression force on the behavior of mucoadhesive buccal tablets. AAPS PharmSciTech, 9, 274-81.

PRASAD, V., SARITHA, T., DIWAN, P. \& CHENNA, T. 2014. PRO-VESICULAR (PV)-BASED GEL FOR THE TOPICAL DELIVERY OF NAPROXEN: PREPARATION, CHARACTERIZATION AND IN VIVO EVALUATION. Asian Journal of Pharmaceutical and Clinical Research, 7, 195-200.

RANA, A. S. \& KUMAR, S. L. 2013. Manufacturing defects of tablets - a review. Journal of Drug Delivery \& Therapeutics, 3, 200-206.

RICHENS, D. T. 1997. The chemistry of aqua ions : synthesis, structure and reactivity : a tour through the periodic table of the elements, Chichester, J. Wiley \& Sons.

ROBERTS, M., FORD, J. L., MACLEOD, G. S., FELL, J. T., SMITH, G. W., ROWE, P. H. \& DYAS, A. M. 2004. Effect of lubricant type and concentration on the punch tip adherence of model ibuprofen formulations. $J$ Pharm Pharmacol, 56, 299-305.

ROJAS, J., CIRO, Y. \& CORREA, L. 2014. Functionality of chitin as a direct compression excipient: An acetaminophen comparative study. Carbohydrate Polymers, 103, 134-139.

SAKER, A. A. \& ALANAZI, F. K. 2013. Oral Solid Dosage Forms. In: FELTON, L. A. (ed.) Remington - Essentials of Pharmaceutics. London, UK: Pharmaceutical Press.

SASTRY, S. V., NYSHADHAM, J. R. \& FIX, J. A. 2000. Recent technological advances in oral drug delivery - a review. Pharm Sci Technolo Today, 3, 138-145.

SAW, H. Y., DAVIES, C. E., JONES, J. R., BRISSON, G. \& PATERSON, A. H. J. 2013. Cohesion of lactose powders at low consolidation stresses. Advanced Powder Technology, 24, 796-800.

SINKA, I. C., MOTAZEDIAN, F., COCKS, A. C. F. \& PITT, K. G. 2009. The effect of processing parameters on pharmaceutical tablet properties. Powder Technology, 189, 276-284.

STEWART, J. C. M. 1980. Colorimetric determination of phospholipids with ammonium ferrothiocyanate. Analytical Biochemistry, 104, 10-14.

SUBRAMANIAN, S., KHAN, I., KORALE, O., ALHNAN, M. A., AHMED, W., NAJLAH, M., TAYLOR, K. M. G. \& ELHISSI, A. 2016. A simple approach to predict the stability of phospholipid vesicles to nebulization without performing aerosolization studies. International Journal of Pharmaceutics, 502, 18-27.

SZALAY, A., KELEMEN, A. \& PINTYE-HÓDI, K. 2015. The influence of the cohesion coefficient (C) on the flowability of different sorbitol types. Chemical Engineering Research and Design, 93, 349-354.

TORCHILIN, V. \& WEISSIG, V. 2003. Liposomes: A Practical Approach, Oxford University Press, New York.

USP. 2015a. Disintegration. Baltimore, USA: United Book Press.

USP. 2015b. Powder Flow. Angle of Repose, Compressability Index and Hausner Ratio. Baltimore, USA: United Book Press.

UZUNOVIC, A. \& VRANIC, E. 2007. Effect of magnesium stearate concentration on dissolution properties of ranitidine hydrochloride coated tablets. Bosn J Basic Med Sci, 7, 279-83.

WONG, A. C.-Y. 2002. Use of angle of repose and bulk densities for powder characterization and the prediction of minimum fluidization and minimum bubbling velocities. Chemical Engineering Science, 57, 26352640.

WONG, M. \& THOMPSON, T. E. 1982. Aggregation of dipalmitoylphosphatidylcholine vesicles. Biochemistry, 21, 4133-9.

YAN-YU, X., YUN-MEI, S., ZHI-PENG, C. \& QI-NENG, P. 2006. Preparation of silymarin proliposome: A new way to increase oral bioavailability of silymarin in beagle dogs. International Journal of Pharmaceutics, 319, 162-168.

ZHAO, N. \& AUGSBURGER, L. L. 2005. Functionality comparison of 3 classes of superdisintegrants in promoting aspirin tablet disintegration and dissolution. AAPS PharmSciTech, 6, E634-40. 

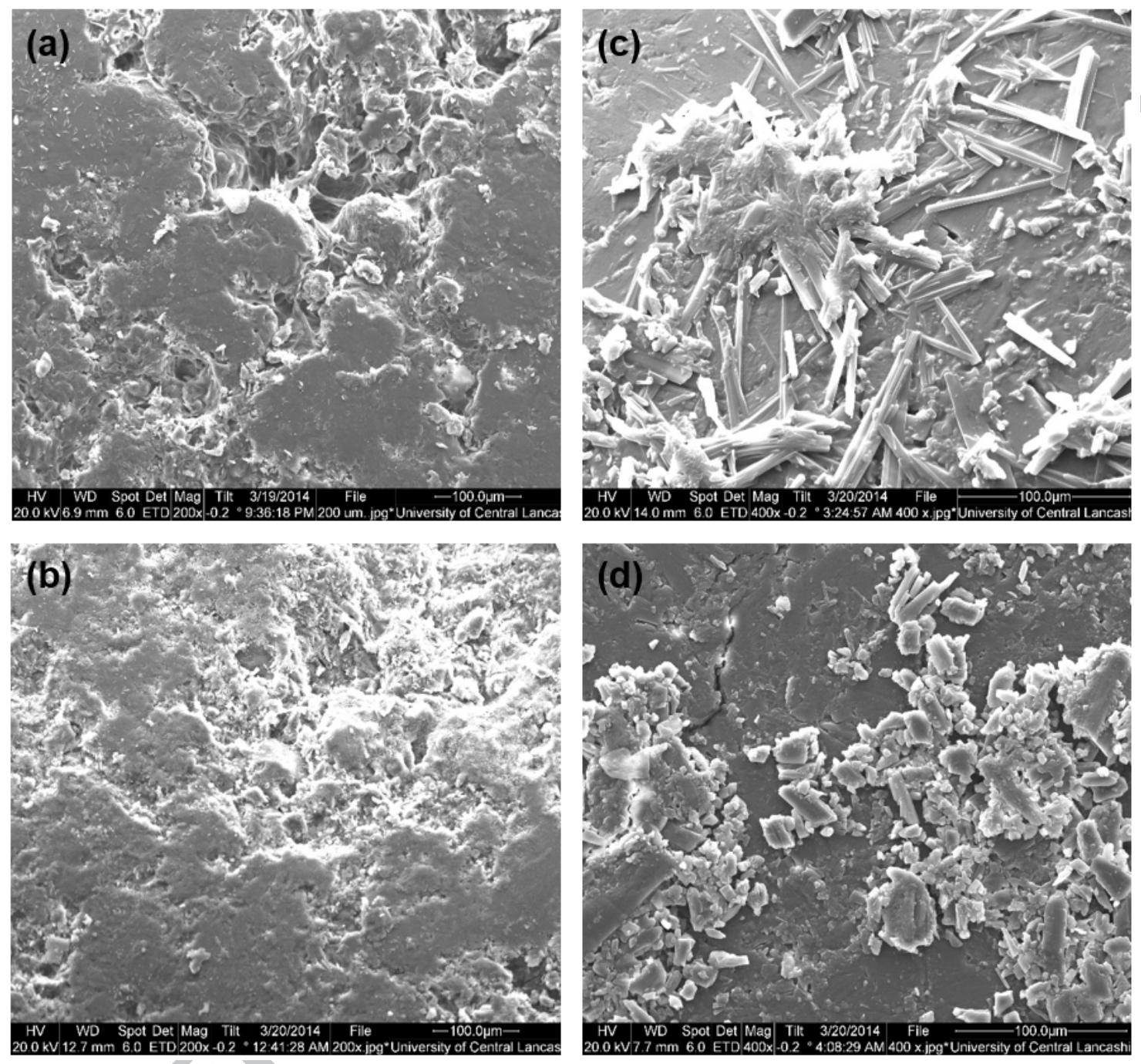

Figure 1: SEM images of sorbitol-based proliposome tablets in (a) 1:10, (b) 1:15, and Dmannitol-based proliposome tablets in a (c) 1:10 and, (d) 1:15 w/w lipid to carrier ratio. These images are typical of three such different experiments 

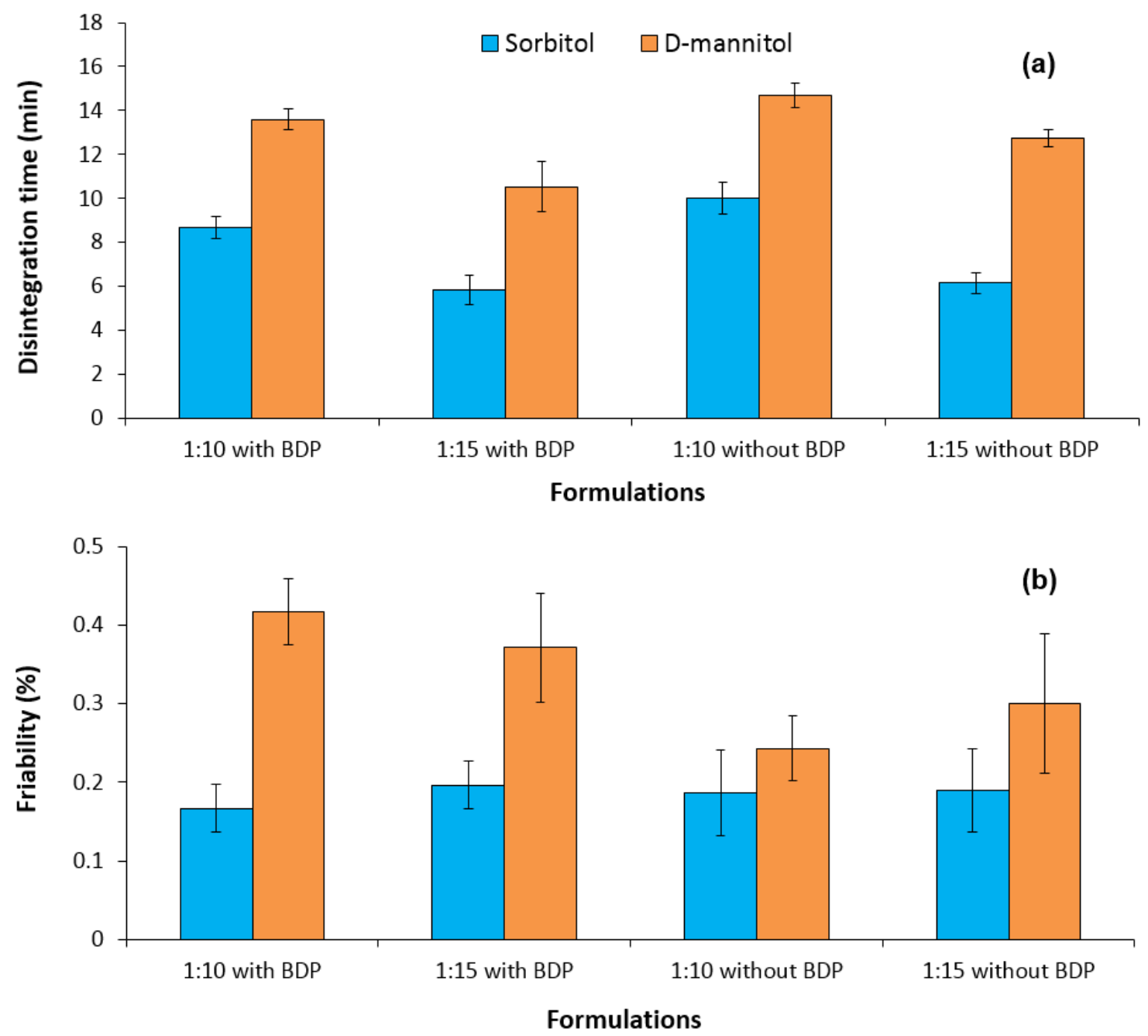

Figure 2: (a) Disintegration time and, (b) percentage weight loss in friability experiments for sorbitol and D-mannitol-based proliposome tablets at 1:10 and 1:15 w/w lipid to carrier ratios; with or without incorporation of BDP. Data are mean $\pm S D, n=3 ; p<0.05$ 


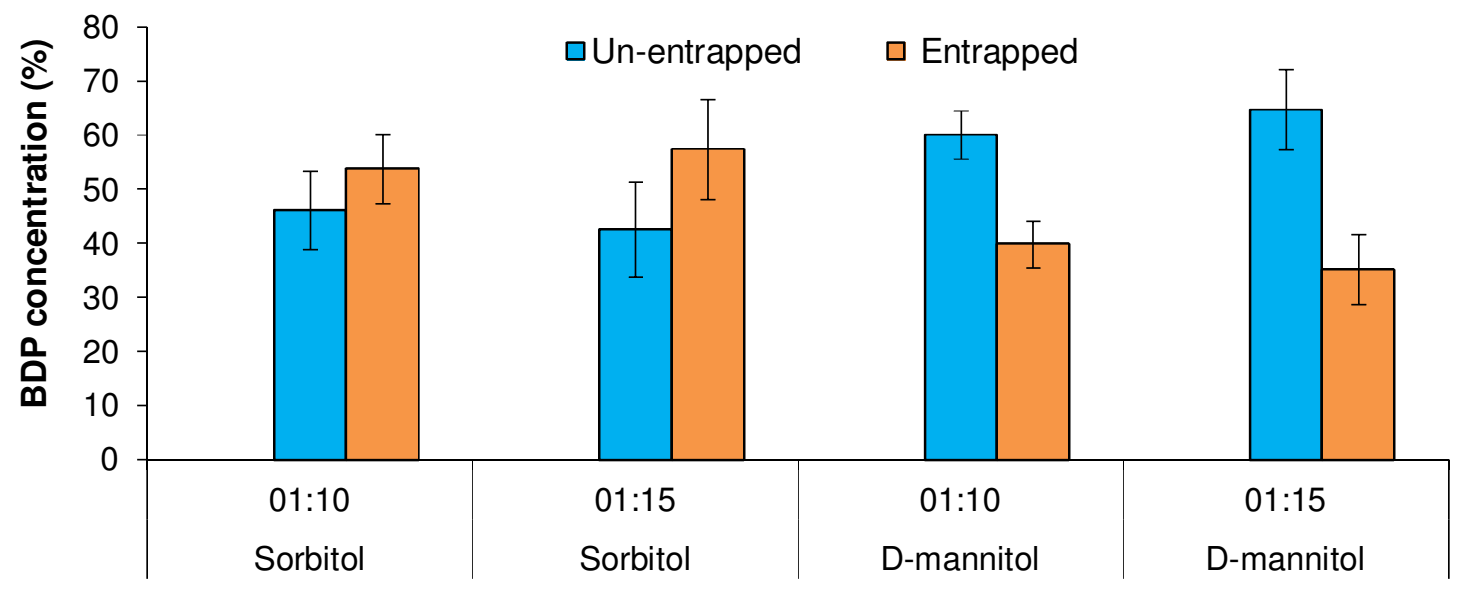

Formulations

Figure 3: BDP concentration analysed for the entrapped, unentrapped and drug spot containing free BDP crystals; via HPLC for both sorbitol and D-mannitol-based proliposome tablets in lipid to carrier ratios of 1:10 and 1:15 w/w. Data are mean $\pm S D, n=3 ; p<0.05$ 

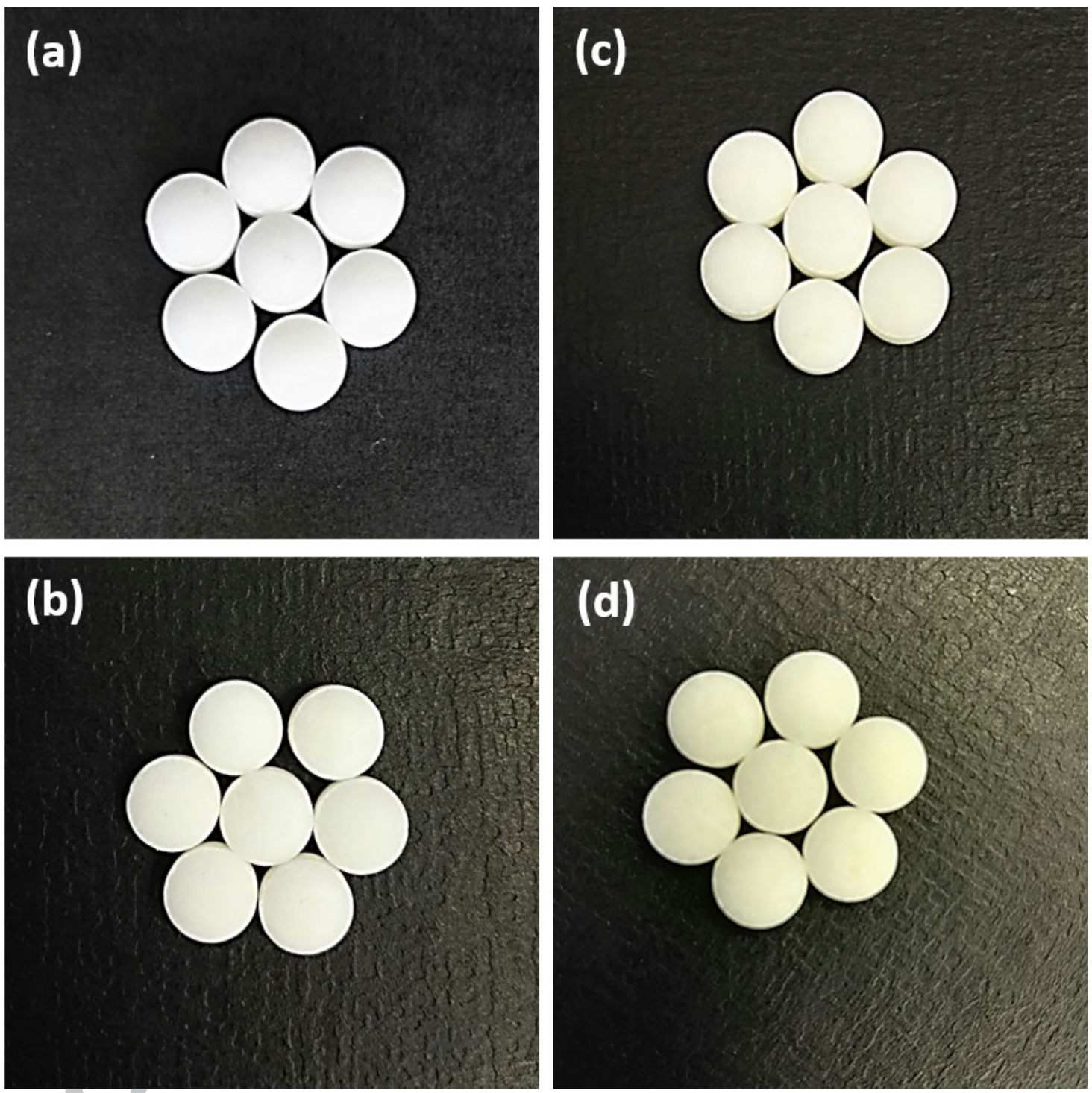

Figure 4: Images of sorbitol-based proliposome in 1:15 w/w ratio, when (a) freshly manufactured as a control sample, followed by keeping them for stability purposes and images were taken after 18 month stability, where these tablets were kept at three different temperature condition i.e. (b) FT, (c) RT and, (d) HT. These images are typical of three such different experiments 

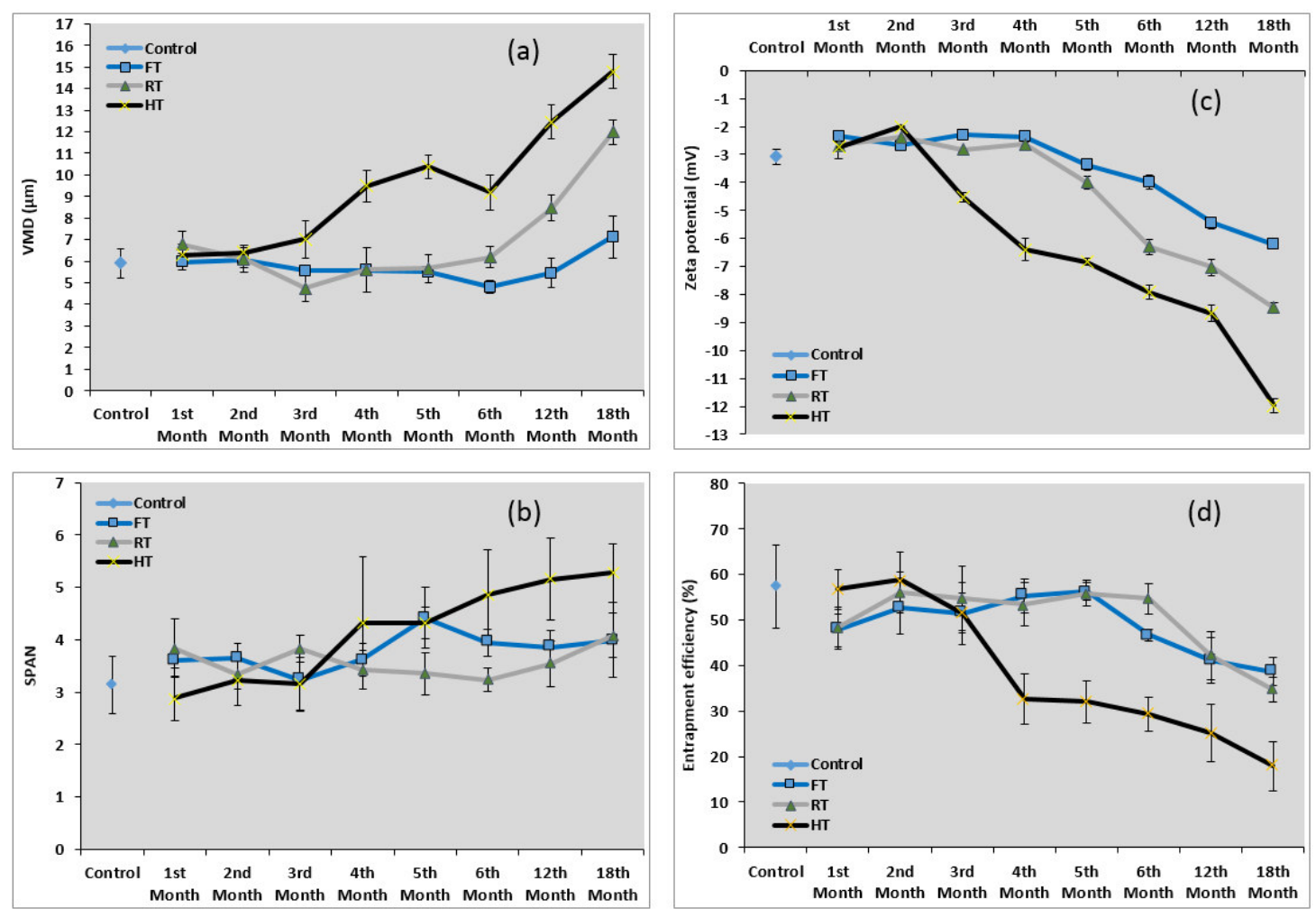

Figure 5: Post hydration of liposome suspension generated from sorbitol-based proliposome in 1:15 w/w ratio was analysed for (a) volume median diameter, (b) SPAN, (c) zeta potential and, (d) entrapment efficiency of BDP was analysed for stability purposes using different temperature conditions of FT, RT and HT for a period of 18 months. Data are mean \pm SD, $n=3$; $\mathrm{p}<0.05$ 
Table 1: Carr's scale of flowability representing flow properties evaluated via compressibility index $(\%)$ and Hausner ratio, and corresponding angle of repose (Carr, 1965)

\begin{tabular}{lccc}
$\begin{array}{l}\text { Compressibility index } \\
(\%)\end{array}$ & Flow character & Hausner ratio & $\begin{array}{c}\text { Angle of repose } \\
\text { (degree) }\end{array}$ \\
\hline $1-10$ & Excellent & $1.00-1.11$ & $25-30$ \\
$11-15$ & Good & $1.12-1.18$ & $31-35$ \\
$16-20$ & Fair & $1.19-1.25$ & $36-40$ \\
$21-25$ & Passable & $1.26-1.34$ & $41-45$ \\
$26-31$ & Poor & $1.35-1.45$ & $46-55$ \\
$32-37$ & Very poor & $1.46-1.59$ & $56-65$ \\
$>38$ & Very, very poor & $>1.60$ & $>66$ \\
\hline
\end{tabular}


Table 2: Compressibility index (\%) and Hausner ratio via tapped density, and Angle of repose of coarse carbohydrate carriers and proliposome powders utilising 1:10 and 1:15 w/w lipid to carrier ratios; for sorbitol and D-mannitol carbohydrate carriers. Data are mean $\pm S D, n=3$

\begin{tabular}{lccccc}
\hline Formulations & $\begin{array}{c}\text { Coarse } \\
\text { powder }\end{array}$ & $\begin{array}{c}\mathbf{1 : 1 0} \\
\text { (with BDP) }\end{array}$ & $\begin{array}{c}\mathbf{1 : 1 0} \\
\text { (without BDP) }\end{array}$ & $\begin{array}{c}\mathbf{1 : 1 5} \\
\text { (with BDP) }\end{array}$ & $\begin{array}{c}\mathbf{1 : 1 5} \\
\text { (without BDP) }\end{array}$ \\
\hline $\begin{array}{l}\text { Compressibility } \\
\text { Index (\%) }\end{array}$ & & & & & \\
$\begin{array}{l}\text { Sorbitol } \\
\text { D-mannitol }\end{array}$ & $17.06 \pm 0.14$ & $14.13 \pm 2.75$ & $11.99 \pm 3.65$ & $17.81 \pm 4.46$ & $20.39 \pm 1.84$ \\
& $34.78 \pm 2.03$ & $17.57 \pm 1.96$ & $17.05 \pm 0.17$ & $18.85 \pm 1.55$ & $18.86 \pm 1.89$ \\
$\begin{array}{l}\text { Hausner } \\
\text { Ratio }\end{array}$ & & & & & \\
Sorbitol & $1.21 \pm 0.01$ & $1.17 \pm 0.04$ & $1.14 \pm 0.05$ & $1.22 \pm 0.05$ & $1.26 \pm 0.03$ \\
$\begin{array}{l}\text { D-mannitol } \\
\text { Angle }\end{array}$ & $1.53 \pm 0.05$ & $1.21 \pm 0.03$ & $1.21 \pm 0.01$ & $1.23 \pm 0.02$ & $1.23 \pm 0.01$ \\
of Repose & & & & & \\
$\begin{array}{l}\text { Sorbitol } \\
\text { D-mannitol }\end{array}$ & $28.33 \pm 0.38$ & $26.61 \pm 0.08$ & $26.08 \pm 0.84$ & $25.62 \pm 1.08$ & $25.86 \pm 0.70$ \\
\hline
\end{tabular}


Table 3: Stewart assay establishing the amount of lipid phase coated on carbohydrate carriers, including: sorbitol or D-mannitol, with formulations ratios of 1:10 and 1:15 w/w lipid to carrier ratio. Data are mean $\pm S D, n=3$

Carrier-based proliposome formulations

Lipid content (\%)

\begin{tabular}{llll}
\hline & $(1: 10 \mathbf{w} / \mathbf{w})$ & & $(1: 15 \mathbf{w} / \mathbf{w})$ \\
\cline { 2 - 3 } Sorbitol & $1.98 \pm 0.12$ & & $1.39 \pm 0.07$ \\
D-mannitol & $2.18 \pm 0.62$ & & $1.64 \pm 0.28$ \\
\hline
\end{tabular}


Table 4: Uniformity of weight (mean weight in $\mathrm{mg}$ ) and hardness tests (i.e. crushing strength in Newton) for sorbitol and D-mannitol-based proliposome tablets in 1:10 and 1:15 w/w lipid to carrier ratios (with and without BDP). Data are mean $\pm S D, n=3$

\begin{tabular}{lccccc}
\hline Parameters & Carrier & $\begin{array}{c}1: 10 \\
\text { (with BDP) }\end{array}$ & $\begin{array}{c}\mathbf{1 : 1 0} \\
\text { (without BDP) }\end{array}$ & $\begin{array}{c}\mathbf{1 : 1 5} \\
\text { (with BDP) }\end{array}$ & $\begin{array}{c}\text { 1:15 } \\
\text { (without BDP) }\end{array}$ \\
\hline $\begin{array}{l}\text { Uniformity of } \\
\text { weight (mg) }\end{array}$ & Sorbitol & $91.12 \pm 2.66$ & $91.97 \pm 2.81$ & $90.17 \pm 4.30$ & $91.15 \pm 3.89$ \\
& D-mannitol & $91.44 \pm 4.21$ & $91.58 \pm 4.64$ & $91.95 \pm 3.95$ & $92.16 \pm 3.60$ \\
$\begin{array}{l}\text { Crushing } \\
\text { strength (N) }\end{array}$ & Sorbitol & $105.42 \pm 9.67$ & $110.76 \pm 9.87$ & $120.67 \pm 12.04$ & $118.56 \pm 11.85$ \\
& D-mannitol & - & - & - & - \\
\hline
\end{tabular}


Table 5: Sorbitol-based proliposome tablets in 1:15 w/w ratio were tested in accordance to British pharmacopeia for uniformity of weight, disintegration test, crushing strength and friability test over a stability period of 18 months (i.e. 1, 2, 3, 4, 5, 6, 12 and 18 months) with keeping a tablets in three different temperature conditions i.e. fridge temperature $\left(\mathrm{FT} ; 6^{\circ} \mathrm{C}\right)$, room temperature $\left(\mathrm{RT} ; 2^{\circ} \mathrm{C}\right)$ and high temperature $\left(\mathrm{HT} ; 40^{\circ} \mathrm{C}\right)$. Data are mean $\pm \mathrm{SD}, \mathrm{n}=3$

\begin{tabular}{|c|c|c|c|c|}
\hline $\begin{array}{c}\text { Formulations and } \\
\text { months }\end{array}$ & $\begin{array}{c}\text { Weight } \\
\text { variation test } \\
(\mathrm{mg})\end{array}$ & $\begin{array}{c}\text { Disintegration } \\
\text { test } \\
\text { (min) }\end{array}$ & $\begin{array}{l}\text { Crushing } \\
\text { strength } \\
\text { (N) }\end{array}$ & $\begin{array}{c}\text { Friability } \\
\text { test } \\
(\%)\end{array}$ \\
\hline Control & $90.17 \pm 4.13$ & $5.85 \pm 0.66$ & $120.67 \pm 12.04$ & $0.20 \pm 0.03$ \\
\hline \multicolumn{5}{|l|}{ FT } \\
\hline 1 & $91.83 \pm 5.53$ & $6.49 \pm 0.57$ & $119.47 \pm 9.47$ & $0.25 \pm 0.06$ \\
\hline 2 & $91.06 \pm 4.97$ & $6.76 \pm 0.64$ & $131.73 \pm 8.71$ & $0.21 \pm 0.05$ \\
\hline 3 & $92.09 \pm 3.46$ & $6.35 \pm 0.06$ & $129.60 \pm 9.56$ & $0.20 \pm 0.02$ \\
\hline 4 & $92.90 \pm 3.54$ & $6.89 \pm 0.36$ & $132.07 \pm 8.58$ & $0.19 \pm 0.05$ \\
\hline 5 & $92.06 \pm 3.89$ & $6.99 \pm 0.80$ & $122.30 \pm 10.97$ & $0.17 \pm 0.04$ \\
\hline 6 & $91.79 \pm 3.40$ & $7.45 \pm 0.16$ & $122.40 \pm 12.02$ & $0.26 \pm 0.04$ \\
\hline 12 & $91.85 \pm 3.95$ & $6.66 \pm 0.69$ & $121.52 \pm 9.45$ & $0.24 \pm 0.03$ \\
\hline 18 & $91.74 \pm 4.29$ & $6.05 \pm 0.74$ & $124.43 \pm 8.26$ & $0.18 \pm 0.02$ \\
\hline \multicolumn{5}{|c|}{ 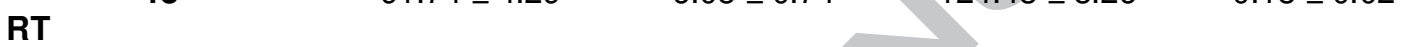 } \\
\hline 1 & $92.49 \pm 4.62$ & $6.46 \pm 0.13$ & $127.03 \pm 11.06$ & $0.24 \pm 0.04$ \\
\hline 2 & $92.53 \pm 3.83$ & $7.02 \pm 0.49$ & $130.93 \pm 9.48$ & $0.19 \pm 0.08$ \\
\hline 3 & $91.69 \pm 3.88$ & $6.12 \pm 0.56$ & $128.43 \pm 8.75$ & $0.20 \pm 0.04$ \\
\hline 4 & $92.16 \pm 3.22$ & $6.53 \pm 0.04$ & $130.80 \pm 10.66$ & $0.24 \pm 0.04$ \\
\hline 5 & $92.54 \pm 3.27$ & $4.79 \pm 0.50$ & $128.23 \pm 11.36$ & $0.19 \pm 0.05$ \\
\hline 6 & $91.75 \pm 3.46$ & $5.09 \pm 0.07$ & $126.10 \pm 9.76$ & $0.23 \pm 0.02$ \\
\hline 12 & $92.54 \pm 3.85$ & $4.97 \pm 0.35$ & $128.42 \pm 8.63$ & $0.18 \pm 0.04$ \\
\hline 18 & $92.03 \pm 4.01$ & $3.92 \pm 0.32$ & $129.75 \pm 9.81$ & $0.19 \pm 0.02$ \\
\hline \multicolumn{5}{|c|}{ 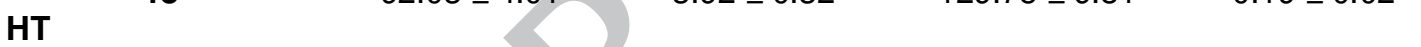 } \\
\hline 1 & $90.76 \pm 5.47$ & $5.89 \pm 0.29$ & $133.97 \pm 11.32$ & $0.20 \pm 0.07$ \\
\hline 2 & $92.15 \pm 4.18$ & $5.41 \pm 0.09$ & $127.77 \pm 14.09$ & $0.23 \pm 0.05$ \\
\hline 3 & $91.05 \pm 3.21$ & $5.31 \pm 0.05$ & $128.83 \pm 11.68$ & $0.18 \pm 0.04$ \\
\hline 4 & $92.45 \pm 3.12$ & $5.23 \pm 0.22$ & $131.27 \pm 10.84$ & $0.22 \pm 0.03$ \\
\hline 5 & $91.09 \pm 3.49$ & $4.71 \pm 0.68$ & $136.72 \pm 11.94$ & $0.21 \pm 0.07$ \\
\hline 6 & $92.91 \pm 3.38$ & $3.79 \pm 0.55$ & $130.27 \pm 10.57$ & $0.24 \pm 0.07$ \\
\hline 12 & $92.24 \pm 3.41$ & $3.46 \pm 0.63$ & $129.58 \pm 9.87$ & $0.20 \pm 0.06$ \\
\hline 10 & $91.54 \pm 4.26$ & $3.06 \pm 0.71$ & $132.72 \pm 10.75$ & $0.18 \pm 0.04$ \\
\hline
\end{tabular}

